\title{
The effect of mycorrhizal seed treatments on rice growth, yield, and tolerance to insect herbivores
}

\author{
Lina Bernaola ${ }^{1}$ (D) Michael J. Stout ${ }^{1}$ (i)
}

Received: 9 March 2020 / Revised: 25 August 2020 / Accepted: 31 August 2020 / Published online: 11 September 2020

(c) The Author(s) 2020

\begin{abstract}
Associations with arbuscular mycorrhizal (AM) fungi can increase or decrease plant resistance to herbivory in different crop systems, but the effects of AM fungi on plant tolerance to pests remain largely unknown. We investigated whether inoculation of rice (Oryza sativa) with AM fungi stimulates plant growth, yield, and/or tolerance to rice water weevil (Lissorhoptrus oryzophilus) injury. Rice plants were exposed to natural infestations of herbivores during early and mid-to-late season over four field experiments. The experiments followed a $2 \times 2$ factorial design consisting of two AM fungi seed treatments (inoculated or non-inoculated with AM fungi) and two insecticide seed treatments (treated or untreated). Inoculation with AM fungi increased root colonization in all four field experiments in rice. Inoculation with AM fungi increased densities of weevil larvae and whiteheads resulting from stemborer infestations, while insecticidal seed treatments significantly reduced densities of weevils and marginally reduced whiteheads. Inoculation with AM fungi increased rice biomass before and after flooding, and a clear but not always significant increase in yield was observed in plants inoculated with AM fungi. However, inoculation with AM fungi did not reduce percent yield losses after herbivory injury. Analyses of nutrient contents in roots and shoots revealed inconsistent effects of inoculation with AM fungi. This study highlights for the first time the potential for AM fungi seed treatments to increase rice tolerance to insect pests by influencing plant biomass and yields.
\end{abstract}

Keywords Oryza sativa $\cdot$ Arbuscular mycorrhizal fungi $\cdot$ Tolerance to herbivory $\cdot$ Rice water weevil $\cdot$ Stem borers

\section{Key message}

- No studies have investigated the tolerance of plants inoculated with AM fungi as microbial agents against rice pests under natural field conditions.

- First report of increased plant biomass and yields despite increased rice water weevil numbers on rice plants inoculated with AM fungi under conventional cultivation regimes.

Communicated by L. R. Jaber.

Electronic supplementary material The online version of this article (https://doi.org/10.1007/s10340-020-01279-7) contains supplementary material, which is available to authorized users.

Lina Bernaola

linabernaola@gmail.com

1 Department of Entomology, Louisiana State University Agricultural Center, Baton Rouge, LA 70803, USA
- However, AM fungi seed treatments did not reduce percent yield losses after herbivory injury.

- This suggests that AM fungi seed treatments can increase plant tolerance to root injury and this approach may be implemented in rice crop production in the USA.

\section{Introduction}

The below-ground herbivores, pathogens, and microbial symbionts associated with the roots of a plant can affect organisms inhabiting above-ground portions of the plant and vice versa (Soler et al. 2012), and these interactions may affect the yield or fitness of plants. Furthermore, associations with soil microorganisms may affect the ability of a plant to recover from herbivore injury. The ability of crop plants to sustain yields under herbivore attack is critical for sustainable crop production. Arbuscular mycorrhizal (AM) fungi, members of the phylum Glomeromycota, are ecologically essential components of soil communities (Borowicz 
2001) and form obligate mutualistic associations with the roots of many plants, including many crops (Smith and Read 2008). AM fungi provide their host plants with nutrients (such as $\mathrm{N}$ and $\mathrm{P}$ ) and water; in return, fungi receive sugars and lipids (Luginbuehl et al. 2017; Smith and Read 2008). Herbivores affect plants by removing biomass and reducing photosynthetic area (Agrawal et al. 2012). Both AM fungi and insect herbivores interact in complex and multifaceted ways with their host plants and can interact with each other via changes they induce in their shared host plant (Gehring and Bennett 2009).

In the context of crop protection, resistance and tolerance are two major strategies that plants employ to reduce the impact of herbivore attack (Mitchell et al. 2016). Resistance comprises plant physical and chemical traits that limit herbivore injury or performance on a plant, while tolerance involves plant traits or physiological processes that reduce the amount of damage (yield loss) per unit herbivore injury (Koch et al. 2016; Mitchell et al. 2016; Stout 2013; Strauss and Agrawal 1999). One advantage of plant tolerance over resistance is that plant tolerance traits typically have no effect on herbivore fitness and therefore are unlikely to impose selection pressure on the herbivore (Stowe et al. 2000; Strauss and Agrawal 1999), suggesting that tolerance traits have better chance to provide more stable and durable insect pest control (Mitchell et al. 2016). Whereas there is extensive information on plant resistance to insects, tolerance is less studied, and the traits or mechanisms responsible are not well understood (Mitchell et al. 2016; Peterson et al. 2017). Tolerance to insect herbivores has been identified in several crop systems including alfalfa, barley, sorghum, maize, wheat, and cotton (Velusamy and Heinrichs 1986), sugarcane, rice, soybean, and potato (Koch et al. 2016), cassava (Byrne et al. 1982), tomato, and strawberry (Schuster et al. 1980). However, tolerance to root-feeding insects (Garrido et al. 2017; Robert et al. 2014, 2015) has received less attention.

Previous studies have demonstrated that AM fungi can modify the pairwise interactions between plants and herbivores (Barber et al. 2013b; Bennett et al. 2006; Kempel et al. 2010; Koricheva et al. 2009; Yang et al. 2014) by altering both plant resistance and tolerance. On the one hand, association with AM fungi has been shown to both increase and decrease resistance to herbivores by inducing plant defense responses or by improving plant quality to herbivores (Cosme et al. 2011; Currie et al. 2011; Gange 2001; Gehring and Bennett 2009; Koricheva et al. 2009). On the other hand, several studies have shown that AM fungi have variable effects on plant tolerance by altering plant nutrient status, photosynthetic activity, and/or plant growth (Bennett and Bever 2007; Bennett et al. 2009; Borowicz 2009, 2013; Gange 2001; Gange and West 1994; Johnson et al. 2016). However, very few studies have examined the role of AM fungi on tolerance to chewing root herbivores (Currie et al. 2011; Gange 2001; Gange et al. 1994).

Modern cereal crops, such as rice, have retained the ancient capacity to interact with AM fungi (Sawers et al. 2008). Rice (Oryza sativa L.) is an important cereal crop in the USA, where mean yields have increased from 6347 kilograms per hectare in 1998 to 8622 kilograms per hectare in 2018 (USDA-ERA 2019). This crop is produced in the seven states of Arkansas, California, Florida, Louisiana, Mississippi, Missouri, and Texas. Despite the high-input agricultural practices used in US rice, rice plants in US production areas are naturally colonized by AM fungi (Bernaola et al. 2018a). At the same time, throughout their crop stages, rice plants interact with a diverse complex of above- and belowground insect herbivores (Lu et al. 2015; Stout et al. 2009). The major early- and mid-to-late-season insect pests of rice in the southern USA are the rice water weevil (Lissorhoptrus oryzophilus; Coleoptera: Curculionidae) and a complex of stem-boring lepidopterans, respectively.

The rice water weevil is the most important insect pest of rice in the USA (Hamm et al. 2010). Adult rice water weevils immigrate to rice fields from overwintering sites in early spring and feed on leaves of young rice plants, resulting in longitudinal scars parallel to the leaf veins of rice plants. After flooding of fields, females lay eggs in leaf sheaths below the water surface. Neonate larvae migrate down to the plant roots, where they feed on flooded roots and pass through four larval instars and a pupal stage (Zou et al. 2004). Feeding on rice roots reduces rice growth and yields (Zou et al. 2004). Yield losses due to heavy weevil infestations can exceed $25 \%$ in a planting season (Stout et al. 2000). In addition, stem-boring lepidopterans can be economically important pests in mid-tillering and reproductive stages of rice growth in Louisiana (Blanche et al. 2009). The rice stem borer complex in Louisiana comprises the Mexican rice borer (Eoreuma loftini; Lepidoptera: Crambidae), the sugarcane borer (Diatraea saccharalis; Lepidoptera: Crambidae), and the rice stalk borer (Chilo plejadellus; Lepidoptera: Crambidae) (Way 2003). Damage occurs when the larvae bore into and tunnel through the rice stems producing symptoms known as deadhearts (dead tillers) and whiteheads (unfilled grains) (Lv et al. 2008; Way 2003). An increase in the occurrence of whiteheads and deadhearts in recent years has been noted in Texas and Louisiana (Way et al. 2006).

In rice, associations with AM fungi result in changes in plant competitive ability (Roger et al. 2013), ecotype-specificity (Diedhiou et al. 2016), functional diversity (Li et al. 2011), nutrient acquisition (Hoseinzade et al. 2016), and growth and gene expression (Angelard et al. 2010; Colard et al. 2011). Although the interactions of rice with AM fungi and with herbivores have mostly been studied separately, a few studies have investigated tripartite interactions among 
AM fungi, herbivores, and rice plants. In particular, a few studies have focused on the effects of AM fungi on the resistance of rice plants to herbivores and pathogens. For instance, Cosme et al. (2011) showed that the rice water weevil oviposited at higher rates on rice plants colonized by the AM fungus Rhizophagus intraradices. The positive effect of the AM symbiosis on the herbivore was attributed to changes in plant nutrition caused by AM fungi colonization. In a recent study, Bernaola et al. (2018b) also showed that inoculation of rice with a commercial AM fungi inoculant increased the susceptibility of rice plants to rice water weevil and two other antagonists, the fall armyworm (Spodoptera frugiperda) and sheath blight (Rhizoctonia solani). Increases in plant susceptibility caused by AM fungi were not associated with changes in the concentrations of essential nutrients in rice plants. The authors suggested that AM fungi colonization influenced susceptibility to pests by influencing defense signaling processes in rice plants. In contrast, Campos-Soriano et al. (2011) reported enhanced resistance to the pathogenic fungus rice blast, Magnaporthe oryzae, in rice plants colonized by AM fungi. The negative effects of symbiosis on the pathogen appeared to arise from both the systemic activation of defense regulatory genes and priming for stronger expression of defense genes during pathogen infection. Although a few studies have shown the beneficial or antagonistic effects of AM fungi on the resistance of rice to some pests, field studies are lacking to characterize the impact of AM fungi on the tolerance of rice to insect herbivores.

The purpose of this study was to investigate whether inoculation by AM fungi increases the growth, yield, and tolerance of rice plants to root injury by the rice water weevil and to stem borer injury under field conditions. To investigate these questions, we used a factorial experimental design with two levels of root injury (ambient injury and reduced injury) and two levels of AM symbiosis (ambient symbiosis and enhanced symbiosis). Root injury was manipulated by treating or not treating rice seeds with a systemic neonicotinoid insecticide, and symbiosis by AM fungi was manipulated by inoculating or not inoculating rice seeds with a commercial formulation of AM fungi. Using this factorial design, we addressed two questions:

1. Does inoculation with AM fungi increase plant biomass, nutrition, and yield in rice?

2. Does inoculation with AM fungi increase tolerance to root herbivory?

The latter hypothesis was tested by investigating differences in plant biomass and yield between insecticide-treated and untreated plots inoculated or not inoculated with AM fungi. We predicted that if inoculation with AM fungi increases tolerance, yield losses from weevil feeding would be lower in plots inoculated with AM fungi than in plots not inoculated with AM fungi. This study represents the first work on the effect of AM fungi on the tolerance of rice to natural field infestations of rice water weevil.

\section{Materials and methods}

\section{Study system}

The cultivar 'CL111' was used as the host plant in all 3 years of the study. 'CL111' is a long-grain, high-yielding, early-maturing conventional rice variety. Seeds of 'CL111' were provided by the breeding and foundation seed program of the Louisiana State University Agricultural Center (LSU AgCenter) H. Rouse Caffey Rice Research Station (Crowley, Acadia, LA, USA). A commercially available mixture of AM fungi (Valent ${ }^{\circledR}$ USA, Walnut Creek, CA, USA) was used in all experiments. This mixture consisted of four endomycorrhizal fungi species (Rhizophagus irregularis, Glomus aggregatum, Funneliformis mosseae, and Claroideoglomus etunicatum) containing spores, hyphae and colonized root fragments (see methodology for more details). AM fungi were applied to seeds before planting as described below. Natural infestations of rice water weevil at early season and stem-boring pests during mid-to-late season were used for the field experiments.

\section{Experimental design}

To evaluate whether inoculation with AM fungi influences rice productivity and tolerance to rice water weevil injury, four field experiments were conducted during the 2016, 2017, and 2018 growing seasons at the LSU AgCenter H. Rouse Caffey Rice Research Station (Acadia Parish, $30^{\circ} 14^{\prime}$ $22^{\prime \prime} \mathrm{N}, 92^{\circ} 20^{\prime} 46^{\prime \prime} \mathrm{W}$ ) on Crowley silt-loam soils. Experiments are referred to below as Experiment-1 (Exp-1) in 2016, Experiment-2 (Exp-2) in 2017, and Experiment-3 (Exp-3) and Experiment-4 (Exp-4) in 2018. All experiments utilized randomized complete block designs incorporating factorial combinations of AM fungi and insecticide treatments as described below. Management practices during those years followed the recommendations of the LSU AgCenter for drill-seeded rice except for $\mathrm{P}$ and $\mathrm{K}$ fertilization and insect management as described below (Blanche et al. 2009).

Each experiment consisted of four treatments with 10 replicates (blocks) of each treatment. Each block consisted of four plots assigned to factorial combinations of two levels of AM fungi seed treatment (+AMF for inoculated with AM fungi and -AMF for non-inoculated with $\mathrm{AM}$ fungi) and two levels of insecticide seed treatment $(+\mathrm{NsI}$ for insecticide treated and -NsI for insecticide untreated) giving a 
total of 40 plots. The insecticide formulation used to treat seeds was NipsIt INSIDE, the active ingredient (AI) of which is the clothianidin $\left(47.8 \%\right.$, Valent ${ }^{\circledR}$ USA Corporation, Walnut Creek, CA). The AM fungi formulation used was MycoApply ${ }^{\circledR}$ EndoMaxx (6.6\%, supplied by Valent Biosciences). Seeds were treated by the manufacturer in each year. Seed treatment rates in all years were $17 \mu \mathrm{g} \mathrm{AI} / \mathrm{seed}$ for clothianidin and $14 \mathrm{~g} \mathrm{AI} /$ ha for MycoApply EndoMaxx. Rice plants were grown from seeds in the field; thus, the soil likely contained native AM fungi. NipsIt INSIDE seed treatments have shown to reduce densities of rice water weevil larvae and pupae in field experiments (Hummel et al. 2014; Hummel and Stout 2009).

Rice seeds were drill-seeded on the dates specified in Table $\mathrm{S} 1$ at a rate of $50 \mathrm{~g}$ of seeds per plot $(67 \mathrm{~kg} / \mathrm{ha})$ in all experiments. Field plots measured $5.4 \mathrm{~m} \times 1.8 \mathrm{~m}$. A soil sample was collected from the rice field before seeding in each year and sent for analysis to the LSU AgCenter Soil Testing \& Plant Analysis Laboratory (STPAL, LSU, Baton Rouge, LA, USA). Soil physical and chemical properties are reported in supporting information Table S2. Fields were surface-irrigated as needed to facilitate plant stand establishment. Permanent flood was applied at the 4-5 leaf (early tillering) stage of rice on the dates specified in Table S1. Nitrogen was applied in all years in a single application, 1 day before permanent flood was established, in the form of urea $(46 \% \mathrm{~N})$ at $134 \mathrm{~kg} \mathrm{~N} / \mathrm{ha}$; fields were not fertilized with $\mathrm{P}$ and $\mathrm{K}$.

For all experiments, densities of rice seedlings in plots were evaluated when plants attained the two- to threeleaf stage (approximately 2 weeks after rice emergence, Table S1) to assess the effect of treatments on seedling densities (Hamm et al. 2014). Densities of plant stands were assessed by counting the number of seedlings present in three or two randomly selected quadrats of $0.09 \mathrm{~m}^{2}$ per plot. Mean stand counts for each plot were used for analysis.

Extent of root colonization by AM fungi was evaluated the day that permanent flood was established (Table S1) in all experiments. Entire plants from each plot were taken using a soil-root core. The core sampler was a metal cylinder with a diameter of $9.2 \mathrm{~cm}$ and a depth of $7.6 \mathrm{~cm}$ attached to a metal handle. Each core sample containing at least one plant was taken from the center of each plot and placed in plastic bags. Roots were rinsed completely free of soil with tap water. Samples were transported to the laboratory. The trypan blue method of Koske and Gemma (1989) was used with minor modifications for root staining of AM fungi colonization. Roots from each sample were cut into $2 \mathrm{~cm}$ pieces and placed in tissue processing cassettes (Ted Pella, Redding, CA, USA). Subsequently, roots were cleared by boiling for $30 \mathrm{~min}$ in $10 \% \mathrm{KOH}$, washing with tap water $5 \mathrm{X}$, then for $20 \mathrm{~min}$ in $2 \% \mathrm{HCl}$, and stained overnight with $0.05 \%$ trypan blue (Sigma-Aldrich, St.
Louis, MO, USA) solution (dissolved in glycerol). Stained root samples were stored in lactoglycerol solution. Percentage of AM fungi colonization was estimated according to the modified method of McGonigle et al. (1990) at 40× magnification to score AM fungal structures, including hyphae, arbuscules, vesicles and spores per root sample (Fig. 1a).

Densities of rice water weevil immatures (larvae and pupae) associated with roots of rice plants were determined on three dates after flooding by taking root-soil core samples (see above) from each plot. Field experiments relied on natural infestations of rice water weevils, which are abundant at the field site. Core sampling was conducted between 3 and 5 weeks after flooding (Table S1). Three core samples were taken from each plot in 2016 and 2017, and two core samples were taken from each plot in 2018. Roots of rice plants from core samples were washed free of soil under medium pressure in a 40 -mesh screen $(0.41 \mathrm{~mm}$ aperture) sieve bucket. Buckets were then placed into basins of salt water, which caused larvae to float to the surface of the salt solution, where they were counted. Pupae were counted as they settled in the bottom of sieve buckets (Figure S1) (N'Guessan et al. 1994). Average numbers of immature weevils found in the two or three soil cores from each plot were calculated and used for analysis.

Incidences of whiteheads resulting from stem borer infestations in reproductive-stage rice was determined by counting the total number of whiteheads in each plot weekly on two (Exp-1 and 2) or five dates (Exp-3 and 4) (Table S1). Plants showing whitehead symptoms were collected, and all tillers with whiteheads were dissected by opening longitudinally with a knife to identify the stem borer species. The numbers of whiteheads collected from plots over 2- or 5 -weeks of sampling were summed to obtain a total number of whiteheads in each plot.

Biomasses of plants (roots and above-ground portions) were assessed twice in each experiment, before and after flood was established (Table S1). Entire plants were pulled by hand from soil. Soil was washed from roots with tap water, and roots were separated from above-ground material and blotted dry with a paper towel. Plant material was stored in a paper bag and placed in a drying oven at $60{ }^{\circ} \mathrm{C}$ for 1 week. Total dry weight (TDW), shoot (stem + leaves) dry weight (SDW), and root dry weight (RDW) were recorded for each plant. Dried plant biomass was submitted to the LSU AgCenter's Soil Testing \& Plant Analysis Laboratory to determine nutrient concentrations in root and shoot tissues. The STPAL determined $\mathrm{N}$ and $\mathrm{C}$ content by dry combustion using a LECO TruSpec ${ }^{\mathrm{TM}} \mathrm{CN}$ analyzer (LECO Corp., St. Joseph, MI, USA), while concentrations of the remaining nutrients $(\mathrm{Ca}, \mathrm{Mg}, \mathrm{S}, \mathrm{P}, \mathrm{K}, \mathrm{Al}, \mathrm{B}, \mathrm{Cu}, \mathrm{Fe}, \mathrm{Mn}$, $\mathrm{Na}$, and $\mathrm{Zn}$ ) were determined by inductively coupled plasma (ICP) analysis. 
Fig. 1 A Root fragments stained with trypan blue showing arbuscular mycorrhizal fungi structures in rice plants. Light micrographs of mycorrhizal inoculated root fragments from some experiments conducted in 2018 show: Hyphae (h), arbuscule (a), vesicle (v), and spore (s). B Effects of inoculation with AM fungi and treatment of seeds with insecticide as well as their interaction on the percent of root fragments colonized by AM fungi in rice plants in four experiments conducted in the field over 3 years (2016-2018). AM fungi colonization at root sampling of CL111 plants grown under the absence (-NsI, light green bars) and presence (+NsI, dark green bars) of insecticide and two AM fungi inoculation treatments $(-\mathrm{AMF}$ and $+\mathrm{AMF})$. Bars represent percentages (mean $\pm \mathrm{SE})$ of root fragments colonized by AM fungi of 10 replications per treatments $(n=10)$. Letters at the column head indicate that means differ significantly (Tukey, $P \leq 0.05$ )

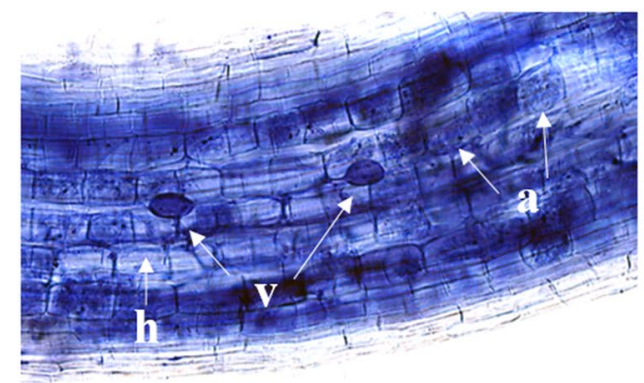

A

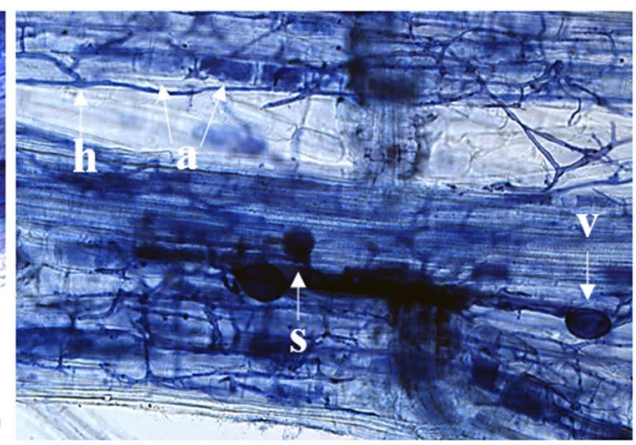

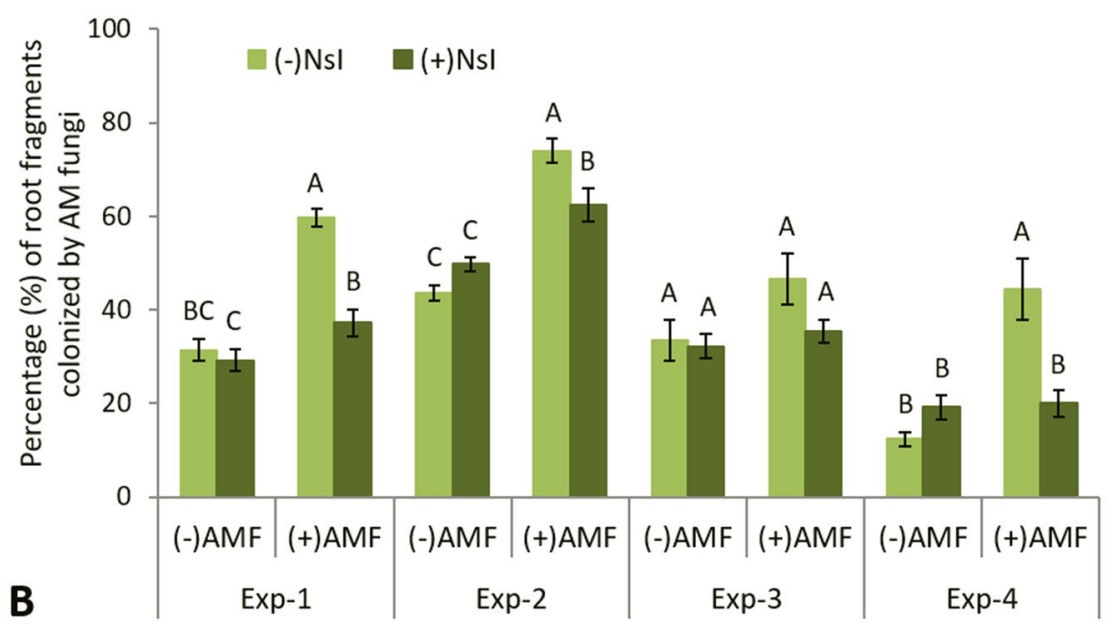

Grain maturities were assessed on two different dates by taking visual ratings of heading and maturity in each plot (Table S1). A plot was considered to have started heading if at least $30 \%$ of panicles were emerged from the leaf sheath. Maturity was defined as the time at which $80 \%$ of all spikelets were ripe (i.e., when grain had lost green color). The average of visual ratings of panicle heading and maturity were determined for each treatment only in Exp-3 and Exp-4 during two consecutive weeks (Table S1) and expressed in percentages for each plot of days after planting (DAP). Entire plots were harvested at grain maturity using a harvester/thresher machine, and grain yields (expressed at 12\% moisture) were recorded.

\section{Statistical analyses}

All statistical analyses were carried out in SAS 9.4 (SAS Institute 2016). The normality and homogeneity of variance for all data were first checked. Data were analyzed using four statistical tests. First, plant stands, numbers of whiteheads, plant biomass, nutrient concentrations, heading, maturity, and yields were analyzed as factorial randomized complete block design experiments with AM fungi, insecticide, and their interaction as fixed effects and block as a random

effect using a two-way analysis of variance (ANOVA) in PROC Mixed. Second, percentages of root fragments colonized by AM fungi were arcsin-square-root-transformed to meet the assumptions of normality and were analyzed using ANCOVA in PROC GLM. Root biomass was included as the covariate in the initial analysis of root colonization to control for variation in root biomass that could influence colonization. Since root biomass did not influence root colonization rates in any of the field experiments, percent root colonization was re-analyzed using a two-way ANOVA in PROC GLM. Third, immature weevil densities over 3 weeks were analyzed separately for each experiment using repeatedmeasures ANOVA in PROC GLM. Means were separated using Tukey's honestly significant difference (HSD) post hoc test.

Finally, percent yield losses from rice water weevil were determined in the following manner. For each block in each experiment, the difference between yields from insecticidetreated $(+\mathrm{NsI})$ plots and yields from insecticide-untreated (-NsI) plots was calculated separately for plots inoculated with AM fungi (+AMF) and plots not inoculated with AM fungi (-AMF). The difference was divided by the yield of the appropriate insecticide-treated plot, and this quotient was multiplied by 100 to calculate a percent yield loss. Percent 
yield losses were analyzed using a one-way ANOVA with AM fungi (+ or - ) as the main effect in PROC MIXED. In addition, a combined analysis using mean yields and percent yield losses from the four experiments was conducted. The following equation was applied in the same way for both inoculated and not inoculated with AM fungi.

Yield loss $(\%)=100 \times \frac{\operatorname{yield}_{(+\mathrm{NsI})}-\operatorname{yield}_{(-\mathrm{NsI})}}{\operatorname{yield}_{(+\mathrm{NsI})}}$.

\section{Results}

\section{Effect of seed treatments on AM fungi root colonization}

Seed treatment with AM fungi successfully increased colonization of roots by AM fungi in all four experiments (Table 1; Fig. 1B). NipsIt INSIDE seed treatment had a negative effect on percent of root colonization by AM fungi in Exp-1 (Table 1; Fig. 1B). In Exp-1, -2, and -4, AM fungi root colonization was significantly lower in the $+\mathrm{AMF}+\mathrm{NsI}$ treatment than in the AMF-only (+AMF -NsI) treatment; this was reflected by a significant effect of NipsIt seed treatment in Exp-1, a marginally significant effect in Exp-4, and a significant AM fungi $x$ NipsIt interaction in Exp-1, -2, and -4 (Table 1; Fig. 1B). These statistical effects suggest that NipsIt interfered with AMF colonization (Table 1).

\section{Effect of seed treatments on plant densities}

AM fungi seed treatment significantly decreased stand counts (seedling densities) of rice plants per $0.09 \mathrm{~m}^{2}$ in Exp-1 (Table S3; Figure S2) but not in Exp-2, Exp-3, or Exp4. NipsIt INSIDE seed treatment did not affect densities of rice seeding in any of the four experiments (Table S3). Seedling densities were significantly affected by the interaction between AM fungi treatment and insecticide treatment in Exp-1, Exp-3, and Exp-4 (Table S3); however, there was no a consistent pattern in the effect of these interactions on seedling densities (Figure S2).

\section{Effect of seed treatments on rice water weevil larval densities}

Densities of rice water weevil larvae and pupae were significantly higher in plots with AM fungi-treated rice plants in Exp-1, Exp-2, and Exp-3 than in plots not inoculated with AM fungi (Table 2; Fig. 2). Increases in weevil densities in $\mathrm{AM}$ fungi-treated plots relative to untreated plots ranged from $12.4 \%$ in Exp-1 to $24.0 \%$ in Exp-2 (Fig. 2). Treatment of seeds with NipsIt INSIDE significantly reduced population densities of immature rice water weevils in all four experiments (Table 2; Fig. 2). Reductions in weevil densities in insecticide-treated plots ranged from $46.4 \%$ in Exp-2 to $77.0 \%$ in Exp-3 (Fig. 2). There was no significant interaction between AM fungi and insecticide seed treatment on weevil densities in any experiment (Table 2). In addition, weevil densities were significantly affected by time of sampling (core 1, 2, or 3) in all four experiments (Table 2; Figure S3). Weevil densities were lowest in the third week after flood (core 1), highest in the fourth week (core 2) and started to decrease in the fifth week (core 3) (Figure S3). Densities of immature weevils were also significantly affected by the interaction of time and AM fungi in Exp-1 (Table 2). Insect densities were higher in AM fungi-treated plots than in nonAM fungi-treated plots in the core sampling taken the third week after flooding, but not in the core samplings taken the fourth and fifth week. Weevil densities were also significantly affected by the interaction of time and insecticide in Exp-1, Exp-3, and Exp-4 (Table 2; Figure S4). In plots untreated with NipsIt INSIDE, insect densities increased over the third week and decreased by the last (fifth) week of sampling, while densities remained steady in insecticidetreated plants (Figure S4).
Table 1 ANOVA of the effects of inoculation with AM fungi (+AMF and $-\mathrm{AMF})$, insecticide seed treatment $(+\mathrm{NsI}$ and $-\mathrm{NsI})$ as well as their interaction on arcsin-square-root-transformed values of the per- centage of rice roots colonized by AM fungi in four experiments conducted in the field over 3 years (2016-2018)

\begin{tabular}{|c|c|c|c|c|c|c|c|c|c|c|c|c|}
\hline \multirow[t]{2}{*}{ Factor } & \multicolumn{3}{|c|}{ Exp-1 } & \multicolumn{3}{|c|}{ Exp-2 } & \multicolumn{3}{|c|}{ Exp-3 } & \multicolumn{3}{|c|}{ Exp-4 } \\
\hline & $d f$ & $F$ & $P$ & $d f$ & $F$ & $P$ & $d f$ & $F$ & $P$ & $d f$ & $F$ & $P$ \\
\hline Block & 9 & 1.74 & 0.129 & 9 & 0.55 & 0.826 & 9 & 0.98 & 0.480 & 4 & 1.25 & 0.340 \\
\hline AM fungi & 1 & 65.17 & $<.0001$ & 1 & 62.82 & $<.0001$ & 1 & 4.50 & 0.043 & 1 & 20.82 & $<.001$ \\
\hline Insecticide & 1 & 29.65 & $<.0001$ & 1 & 1.22 & 0.279 & 1 & 2.09 & 0.159 & 1 & 4.48 & 0.056 \\
\hline $\begin{array}{l}\text { AM fungi } x \\
\text { Insecticide }\end{array}$ & 1 & 19.39 & 0.0002 & 1 & 10.95 & 0.003 & 1 & 1.63 & 0.213 & 1 & 18.98 & $<.001$ \\
\hline Error & 27 & & & 27 & & & 27 & & & 12 & & \\
\hline
\end{tabular}

Bold numbers indicate significant effects 
Table 2 Repeated measures ANOVA of the effects of time (core sampling date), inoculation with AM fungi (+AMF and -AMF), treatment of seeds with insecticide $(+\mathrm{NsI}$ and $-\mathrm{NsI})$ as well as their interactions on densities of larvae and pupae of rice water weevil in experiments conducted in the field over 3 years (2016-2018)

\begin{tabular}{|c|c|c|c|c|c|c|c|c|c|c|c|c|}
\hline \multirow[t]{2}{*}{ Factor } & \multicolumn{3}{|l|}{ Exp-1 } & \multicolumn{3}{|l|}{ Exp-2 } & \multicolumn{3}{|l|}{ Exp-3 } & \multicolumn{3}{|l|}{ Exp-4 } \\
\hline & $d f$ & $F$ & $P$ & $d f$ & $F$ & $P$ & $d f$ & $F$ & $P$ & $d f$ & $F$ & $P$ \\
\hline AM fungi & 1,99 & 4.12 & 0.045 & 1,99 & 10.0 & 0.002 & 1,99 & 6.45 & 0.013 & 1,99 & 2.46 & 0.120 \\
\hline Insecticide & 1,99 & 269 & $<.0001$ & 1,99 & 110 & $<.0001$ & 1,99 & 240 & $<.0001$ & 1,99 & 276 & $<.0001$ \\
\hline AM fungi* Insecticide & 1,99 & 1.91 & 0.170 & 1,99 & 2.25 & 0.137 & 1,99 & 2.28 & 0.134 & 1,99 & 1.35 & 0.247 \\
\hline Time (core) & 2,99 & 15.3 & $<.0001$ & 2,99 & 79.4 & $<.0001$ & 2,99 & 8.76 & 0.0003 & 2,99 & 14.9 & $<.0001$ \\
\hline Time* AM fungi & 2,99 & 4.58 & 0.013 & 2,99 & 1.09 & 0.342 & 2,99 & 0.30 & 0.740 & 2,99 & 0.35 & 0.708 \\
\hline Time * Insecticide & 2,99 & 6.35 & 0.003 & 2,99 & 1.61 & 0.206 & 2,99 & 16.9 & $<.0001$ & 2,99 & 6.06 & 0.003 \\
\hline Time $*$ AM fungi $*$ Insecticide & 2,99 & 0.42 & 0.656 & 2,99 & 0.51 & 0.600 & 2,99 & 1.25 & 0.289 & 2,99 & 0.43 & 0.654 \\
\hline
\end{tabular}

Bold numbers indicate significant effects
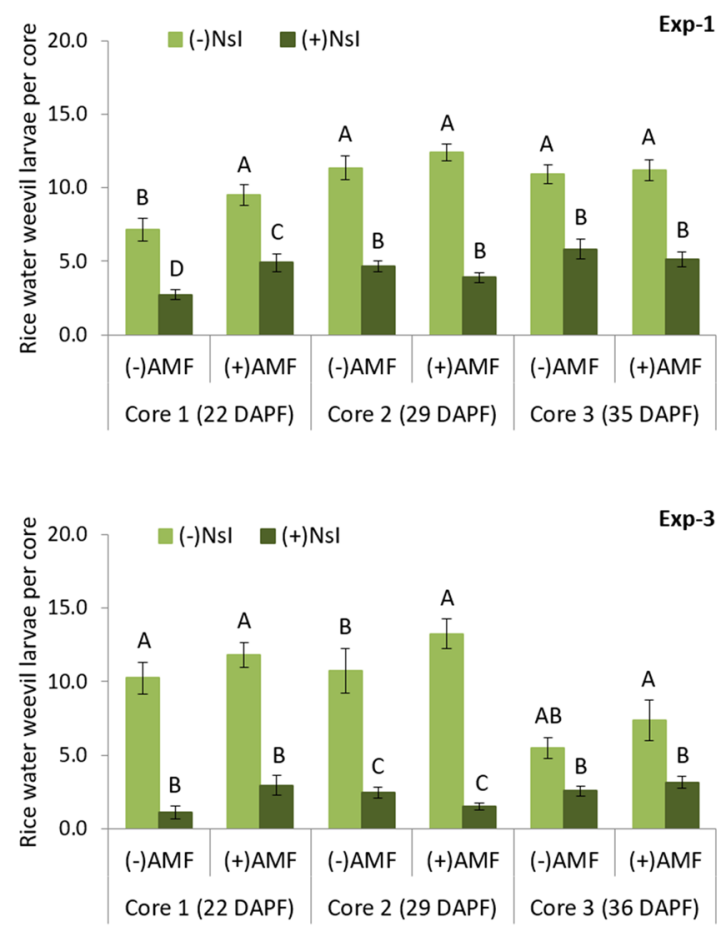

Fig. 2 Effects of inoculation with AM fungi and treatment of seeds with insecticide on densities of rice water weevil in rice plots for four experiments conducted in the field over 3 years (2016-2018). Weevil densities in CL111 plants grown under the absence (-NsI, light green bars) and presence (+NsI, dark green bars) of insecticide and two

\section{Effect of seed treatments on whitehead numbers}

Numbers of whiteheads per plot were used as a measure of stem borer infestation in all four experiments (Figure S5). About $70 \%$ of stem borer larvae collected after dissecting rice stems were found to be Mexican rice borers, with the remaining larvae a mix of sugarcane borers and rice stalk borers (data not shown). AM fungi seed treatment significantly increased whitehead numbers compared to non-AM
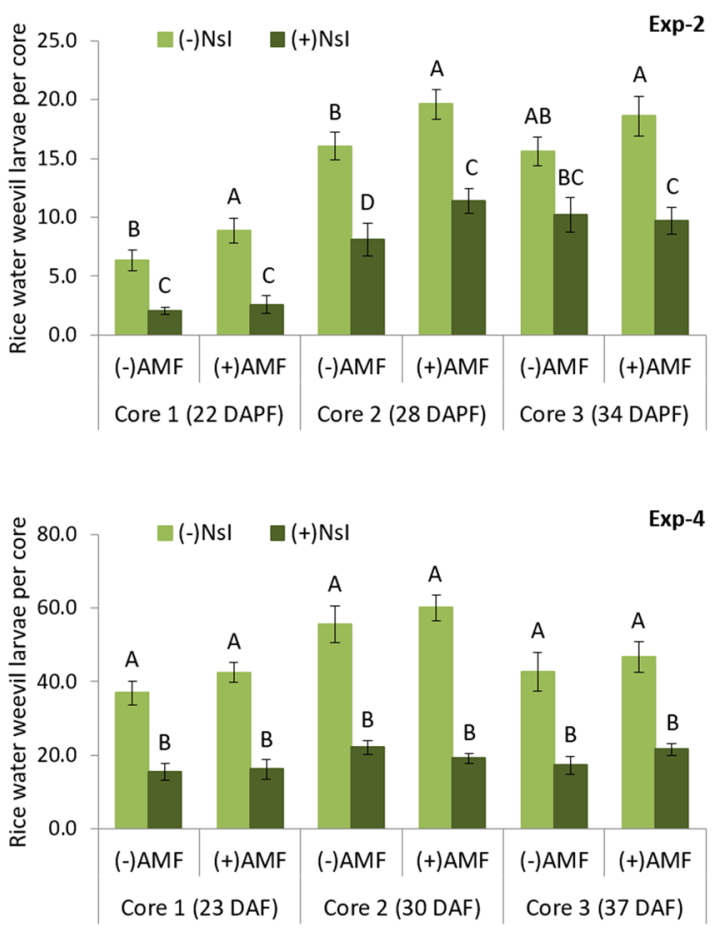

AM fungi inoculation treatments ( $-\mathrm{AMF}$ and $+\mathrm{AMF}$ ). Bars represent densities (larvae and pupae per core sample \pm SE) of 10 replications $(n=10)$. Letters at the column head indicate means that differ significantly between treatments (Tukey, $P \leq 0.05$ )

fungi rice plots in Exp-1 and Exp-4 (Table 3). Increases in number of whiteheads in AM fungi-treated plots ranged from $35.7 \%$ in Exp-4 to 100.0\% in Exp-2 (Fig. 3). NipsIt INSIDE seed treatment significantly reduced whitehead numbers by $50.3 \%$ in treated plots compared to untreated rice plots only in Exp-4 (Fig. 3). There were no significant interactions between AM fungi and insecticide treatments on whitehead numbers in any year (Table 3). 
Table 3 Results of ANOVA for effects of inoculation with AM fungi (+AMF and -AMF), treatment of seeds with insecticide (+NsI and -NsI) as well as their interaction on numbers of whiteheads produced by stem borers in experiments conducted in the field over 3 years (2016-2018)

\begin{tabular}{|c|c|c|c|c|c|c|c|c|c|c|c|c|}
\hline \multirow[t]{2}{*}{ Factor } & \multicolumn{3}{|l|}{ Exp-1 } & \multicolumn{3}{|l|}{ Exp-2 } & \multicolumn{3}{|l|}{ Exp-3 } & \multicolumn{3}{|l|}{ Exp-4 } \\
\hline & $d f$ & $F$ & $P$ & $d f$ & $F$ & $P$ & $d f$ & $F$ & $P$ & $d f$ & $F$ & $P$ \\
\hline Block & 9,67 & 1.86 & 0.07 & 9,67 & 0.62 & 0.77 & 9,187 & 0.92 & 0.51 & 9,187 & 2.62 & 0.007 \\
\hline AMF & 1,67 & 5.54 & 0.02 & 1,67 & 2.80 & 0.09 & 1,187 & 1.55 & 0.22 & 1,187 & 4.23 & 0.04 \\
\hline Insecticide & 1,67 & 0.24 & 0.63 & 1,67 & 1.47 & 0.23 & 1,187 & 2.40 & 0.12 & 1,187 & 36.5 & $<.0001$ \\
\hline $\mathrm{AMF}^{*}$ Insecticide & 1,67 & 0.24 & 0.63 & 1,67 & 0.40 & 0.53 & 1,187 & 1.28 & 0.26 & 1,187 & 1.70 & 0.19 \\
\hline
\end{tabular}

Bold numbers indicate significant effects

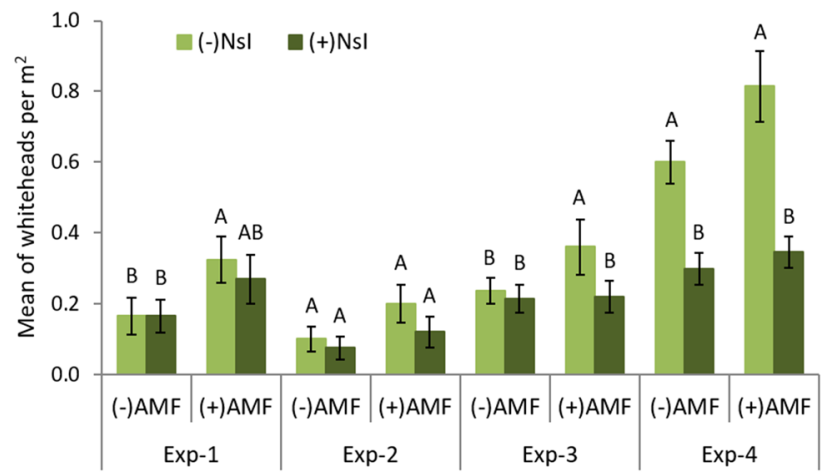

Fig. 3 Effects of inoculation with AM fungi and treatment of seeds with insecticide on numbers of whiteheads produced by stem borers in experiments conducted in the field over 3 years (2016-2018). Whitehead densities in CL111 plants grown under the absence (-NsI, light green bars) and presence (+NsI, dark green bars) of insecticide and two AM fungi inoculation treatments (-AMF and +AMF). Bars represent densities of whiteheads (whiteheads per plot \pm SE) of 10 replications $(n=10)$. Letters at the column head indicate means that differ significantly (Tukey, $P \leq 0.05$ )

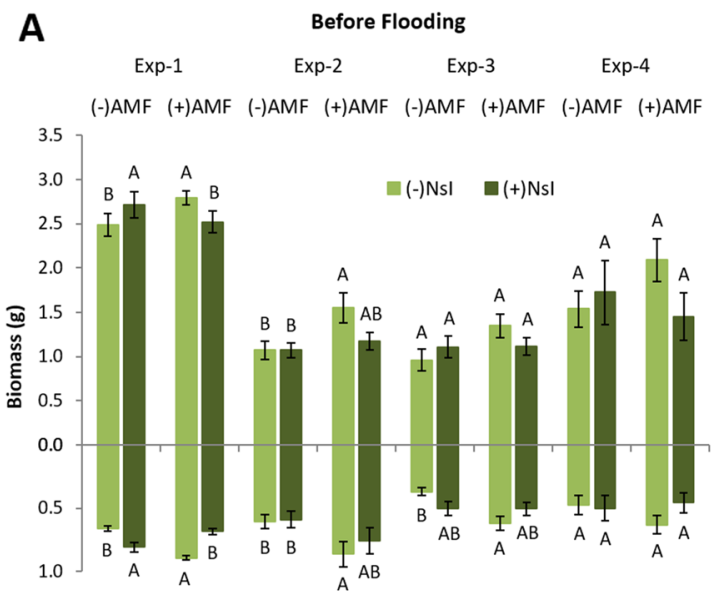

Fig. 4 Effects of inoculation with AM fungi (+AMF and -AMF) and treatment of seeds with insecticide (+NsI and $-\mathrm{NsI})$ on shoot (above $\mathrm{x}$-axis) and root (below $\mathrm{x}$-axis) dry biomass weights of rice plants sampled from plots twice: $\mathbf{A}$ before and $\mathbf{B}$ after flooding, of

\section{Effect of seed treatments on plant biomass}

Before flooding, inoculation of rice seeds with AM fungi had a greater influence on root biomass than on shoot biomass (Fig. 4A). RDW was greater in AM fungi treatments in Exp-1, Exp-2, and Exp-3 (Table 4; Fig. 4A) and TDW was greater in AM fungi treatments in Exp-2 and Exp-3 (Table 4; Figure S6A). SDW, on the other hand, was increased by inoculation with AM fungi before flooding only in Exp-2 (Fig. 4A). There were no main effects of insecticide treatment on plant biomass in any of the pre-flood samplings (Table 4). In addition, the interaction between AM fungi and insecticide treatments significantly influenced the TDW, SDW, and RDW in Exp-1; TDW and RDW in Exp-3; and SDW in Exp-4 (Table 4 and Table S4). These interactions suggest that AM fungi treatments did not impact plant biomass significantly in the presence of NipsIt INSIDE treatments; however, AM fungi had a positive impact on biomass in NipsIt INSIDE-untreated plots.

B

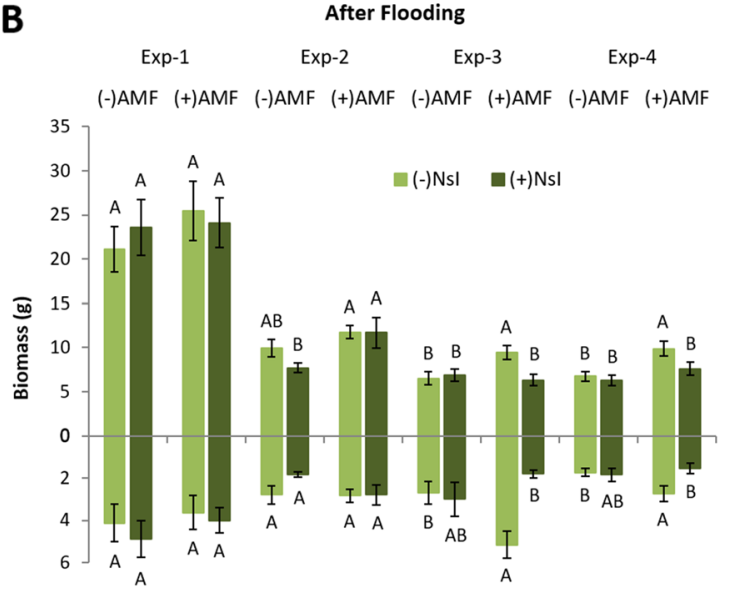

four experiments conducted in the field over 3 years (2016-2018). Bars represent dry biomass weight (g per plant \pm SE) of 10 replications $(n=10)$. Letters at the column head indicate means that differ significantly (Tukey, $P \leq 0.05$ ) 
Table 4 ANOVA of the effects of inoculation with AM fungi (+AMF and -AMF), treatment of seeds with insecticide $(+\mathrm{NsI}$ and $-\mathrm{NsI})$ as well as their interactions on the dry weight in total (TDW), shoot (SDW) and root (RDW) biomass collected twice, before (B.F.) and after (A.F.) flooding were established, in experiments conducted in the field over 3 years (2016-2018)

\begin{tabular}{|c|c|c|c|c|c|c|c|}
\hline \multirow[t]{2}{*}{ Trial } & \multirow[t]{2}{*}{ Fixed effect } & \multicolumn{2}{|l|}{ TDW } & \multicolumn{2}{|l|}{ SDW } & \multicolumn{2}{|l|}{ RDW } \\
\hline & & $F_{1,27}$ & $P$ & $F_{1,27}$ & $P$ & $F_{1,27}$ & $P$ \\
\hline \multirow[t]{9}{*}{ Exp-1 } & $\mathrm{AM}$ fungi & & & & & & \\
\hline & B.F. & 0.67 & 0.42 & 0.23 & 0.63 & 4.06 & 0.05 \\
\hline & A.F. & 0.19 & 0.66 & 0.54 & 0.47 & 0.62 & 0.44 \\
\hline & Insecticide & & & & & & \\
\hline & B.F. & 0.19 & 0.67 & 0.05 & 0.83 & 1.52 & 0.23 \\
\hline & A.F. & 0.07 & 0.79 & 0.03 & 0.87 & 0.41 & 0.53 \\
\hline & AM fungi* I & & & & & & \\
\hline & B.F. & 10.20 & 0.004 & 4.67 & 0.039 & 44.64 & $<.0001$ \\
\hline & A.F. & 0.26 & 0.62 & 0.32 & 0.57 & 0.04 & 0.83 \\
\hline \multirow[t]{9}{*}{ Exp-2 } & AM fungi & & & & & & \\
\hline & B.F. & 8.47 & 0.007 & 6.86 & 0.01 & 8.67 & 0.007 \\
\hline & A.F. & 7.57 & 0.01 & 8.91 & 0.006 & 2.23 & 0.15 \\
\hline & Insecticide & & & & & & \\
\hline & B.F. & 2.07 & 0.16 & 2.86 & 0.10 & 0.72 & 0.40 \\
\hline & A.F. & 1.76 & 0.20 & 1.37 & 0.25 & 2.19 & 0.15 \\
\hline & AM fungi $* I$ & & & & & & \\
\hline & B.F. & 1.81 & 0.19 & 2.83 & 0.10 & 0.41 & 0.53 \\
\hline & A.F. & 1.53 & 0.23 & 1.21 & 0.28 & 1.85 & 0.19 \\
\hline \multirow[t]{9}{*}{ Exp-3 } & AM fungi & & & & & & \\
\hline & B.F. & 4.57 & 0.04 & 2.74 & 0.11 & 8.73 & 0.006 \\
\hline & A.F. & 3.26 & 0.08 & 4.46 & 0.044 & 1.18 & 0.29 \\
\hline & Insecticide & & & & & & \\
\hline & B.F. & 0.05 & 0.82 & 0.13 & 0.72 & 0.04 & 0.85 \\
\hline & A.F. & 8.23 & 0.008 & 5.89 & 0.02 & 6.81 & 0.01 \\
\hline & AM fungi $* I$ & & & & & & \\
\hline & B.F. & 4.27 & 0.049 & 2.55 & 0.12 & 8.19 & 0.008 \\
\hline & A.F. & 12.54 & 0.002 & 9.49 & 0.005 & 9.86 & 0.003 \\
\hline \multirow[t]{9}{*}{ Exp-4 } & $\mathrm{AM}$ fungi & & & & & & \\
\hline & B.F. & 0.53 & 0.47 & 0.43 & 0.52 & 0.78 & 0.39 \\
\hline & A.F. & 16.26 & 0.0004 & 18.18 & 0.0002 & 2.00 & 0.17 \\
\hline & Insecticide & & & & & & \\
\hline & B.F. & 1.29 & 0.27 & 1.17 & 0.29 & 1.39 & 0.25 \\
\hline & A.F. & 8.93 & 0.006 & 6.91 & 0.01 & 4.66 & 0.04 \\
\hline & AM fungi * I & & & & & & \\
\hline & B.F. & 3.72 & 0.06 & 3.91 & 0.06 & 2.41 & 0.13 \\
\hline & A.F. & 5.92 & 0.02 & 2.99 & 0.09 & 6.84 & 0.01 \\
\hline
\end{tabular}

Bold numbers indicate significant effects
In contrast to the results observed before flooding, inoculation with AM fungi had a greater effect on shoot weights than root weights after flooding (Fig. 4B). After flooding, AM fungi treatments significantly increased the TDW (Table 4; Figure S6B) and SDW in Exp-2, the SDW in Exp-3 (Table 4; Fig. 4B), and the TDW and SDW in Exp-4 (Table 4; Fig. 4B and Figure S6B). NipsIt INSIDE seed treatment positively influenced the SDW and RDW in Exp-3, and TDW, SDW and RDW in Exp-4 (Table 4; Fig. 4B; Figure S6B). Moreover, the interaction between AM fungi and insecticide treatments significantly influenced the TDW, SDW, and RDW in Exp-3 (Table S5), and TDW and RDW in Exp-4 (Table S5). These interactions suggest that, after flooding, AM fungi treatments still influence plant growth significantly regardless of the presence of insecticide treatments.

\section{Effect of seed treatments on concentrations of plant nutrients}

The effects of AM fungi and insecticide seed treatments on concentrations of nutrients in rice shoots and roots were 
inconsistent, and only a handful of significant responses were observed. Before flooding, treatment with AM fungi significantly increased shoot $\mathrm{N}$ concentrations in Exp-1 and root $\mathrm{N}$ concentrations in Exp-3 (Table S6). Also, inoculation with AM fungi significantly decreased shoot $\mathrm{N}$ concentrations in Exp-2 and Exp-3 and root $\mathrm{N}$ concentrations in Exp-1 (Table S6). Insecticide seed treatment significantly decreased shoot $\mathrm{N}$ and increased root $\mathrm{N}$ concentrations in Exp-3 (Table S6). AM fungi treatment significantly decreased shoot $\mathrm{P}$ concentrations in Exp-2 and decreased root $\mathrm{P}$ concentrations in Exp-3 (Table S6). Treatment with AM fungi significantly increased shoot $\mathrm{C}$ concentrations in Exp-1 and decreased shoot $\mathrm{C}$ concentrations in Exp-2 (Table S6). NipsIt INSIDE seed treatment significantly decreased shoot $\mathrm{C}$ concentrations in Exp-2 and increased root $\mathrm{C}$ concentrations in Exp-3 (Table S6). Additionally, the interaction between inoculation with AM fungi and insecticide seed treatments significantly influenced shoot and root $\mathrm{P}$ concentrations in Exp-2, as well as $\mathrm{N}$ and $\mathrm{C}$ concentrations of shoots and roots in Exp-3 (Table S7).

The effects of treatments on nutrient concentrations after flooding were also inconsistent. Treatment with AM fungi significantly increased shoot $\mathrm{N}$ concentrations in Exp-4 (Table S6). NipsIt INSIDE seed treatment significantly increased root $\mathrm{N}$ concentrations in Exp-1 and -3 (Table S6). Insecticide treatment significantly increased shoot $\mathrm{P}$ concentrations in Exp-4, and root $\mathrm{P}$ concentrations in Exp-1 and -2 (Table S6). Treatment with AM fungi significantly decreased shoot $\mathrm{C}$ concentrations in Exp-3 and increased shoot $C$ concentrations in Exp-4 (Table S6). Insecticide seed treatment significantly decreased shoot $\mathrm{C}$ concentrations in Exp-2 and -4, and increased root $C$ concentrations in Exp-1 and -3 (Table S6). The interaction between AM fungi and insecticide treatment significantly influenced root $\mathrm{P}$ concentrations in Exp-1, shoot $\mathrm{N}$ concentrations and root N, P, and $\mathrm{C}$ concentrations in Exp-3, and shoot $\mathrm{N}$ and $\mathrm{C}$ concentrations in Exp-4 (Table S8).

\section{Effect of seed treatments on yields and tolerance}

Data for percentages of heading and maturity were not taken in Exp-1 and Exp-2. Neither AM fungi seed treatment nor the interaction of AM fungi and insecticide seed treatments altered heading or maturity of rice plants in Exp-3 and Exp-4 (Table 5; Fig. 5A). In contrast, insecticide seed treatment significantly accelerated heading at 88 DAP and maturity at 102 DAP in Exp-4 (Table 5). At 88 DAP, panicle heading in insecticide-treated plots was $32.8 \%$ earlier when compared to untreated plots in Exp-4 (Fig. 5A). At 102 DAP, panicle maturity in NipsIt INSIDE-treated plots hastened $10.0 \%$ when compared to untreated plots in Exp-4 (Fig. 5A).

Yields from rice plots inoculated with AM fungi were significantly higher than from plots not treated with AM fungi

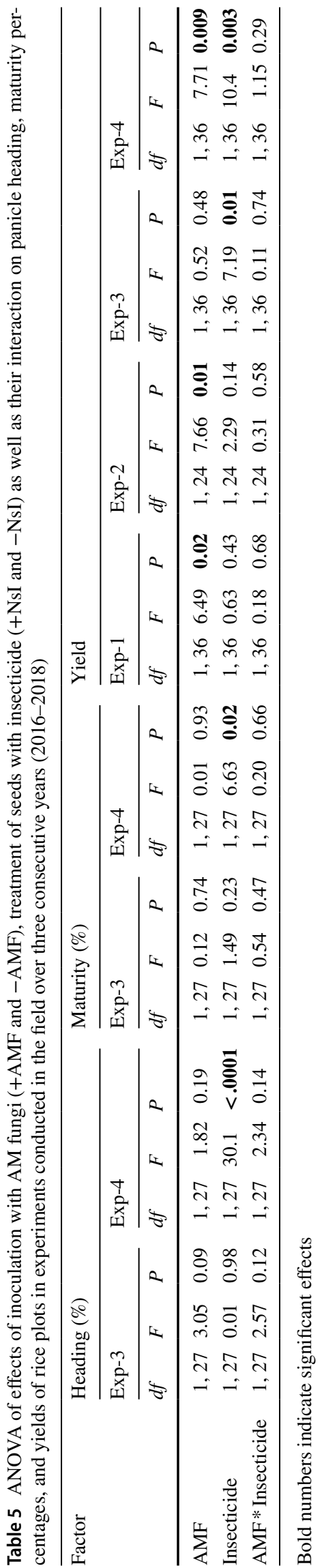




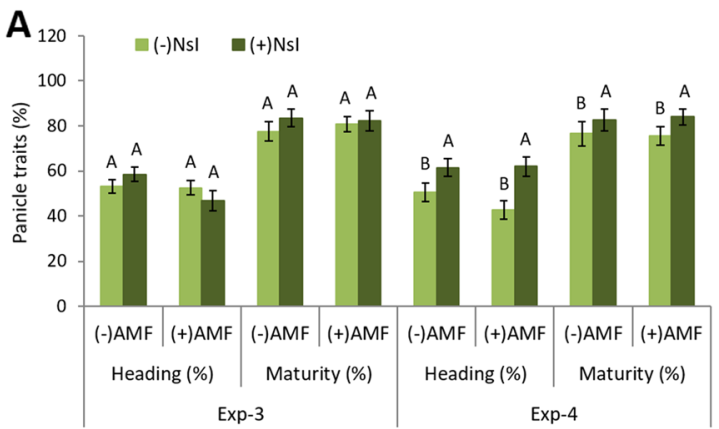

Fig. 5 Effects of inoculation with AM fungi (+AMF and -AMF) and treatment of seeds with insecticide (+NsI and $-\mathrm{NsI}$ ) of panicle heading, maturity, and on yields of rice plots of field experiments conducted over three consecutive years (2016-2018). A Percent of panicle heading and maturity in two field experiment conducted in 2018.

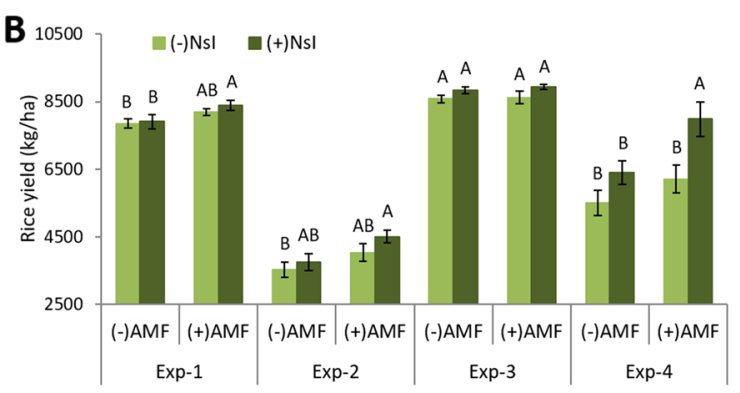

Bars represent percentages (mean $\pm \mathrm{SE}$ ) of 10 replications of heading or maturity $(n=10)$. B Yields were adjusted to $12 \%$ moisture. Bars represent total yields $(\mathrm{kg} / \mathrm{ha}$ per plot $\pm \mathrm{SE})$ of 10 replications per experiment $(n=10)$. Letters at the column head indicate means that differ significantly (Tukey, $P \leq 0.05$ )
Table 6 Yield losses $(\mathrm{kg} /$ ha \pm SE) attributable to rice water weevil root injury in four experiments conducted in the field over 3 years (2016-2018)

\begin{tabular}{lllll}
\hline Treatment & \multicolumn{4}{l}{ Yield loss $(\mathrm{kg} / \mathrm{ha} \pm \mathrm{SE})$} \\
\cline { 2 - 5 } & Exp-1 & Exp-2 & Exp-3 & Exp-4 \\
\hline +AMF & $194.34 \pm 198.97 \mathrm{a}$ & $473.00 \pm 334.54 \mathrm{a}$ & $342.03 \pm 174.46 \mathrm{a}$ & $1782.73 \pm 775.43 \mathrm{a}$ \\
$-\mathrm{AMF}$ & $60.57 \pm 334.07 \mathrm{a}$ & $218.20 \pm 333.22 \mathrm{a}$ & $255.17 \pm 167.24 \mathrm{a}$ & $893.57 \pm 513.32 \mathrm{a}$ \\
$F^{c}$ & 0.14 & 0.29 & 0.13 & 0.91 \\
$P>F$ & 0.720 & 0.597 & 0.722 & 0.352 \\
\hline
\end{tabular}

Non-AMF represent yield losses that were calculated by subtracting yields in plots not treated with insecticide from yields in plots treated with insecticide; this difference was calculated separately for plots inoculated with AM fungi and plots not inoculated with AM fungi. Numbers represent yield losses of 10 replications per experiment $(n=10)$

${ }^{\mathrm{a}} \operatorname{Exp}-1: d f=1,9$; Exp-2: 1, 16; Exp-3: 1, 9; and Exp-4: 1, 18 in Exp-1, Exp-2, and Exp-4 (Table 5). Yields from AM fungi plots were higher by $410 \mathrm{~kg} / \mathrm{ha}$ in Exp-1, $632 \mathrm{~kg} / \mathrm{ha}$ in Exp2, and $1151 \mathrm{~kg} / \mathrm{ha}$ in Exp-4. No effect of AM fungi treatment on yield was observed in Exp-3. NipsIt INSIDE seed treatment significantly affected yields in Exp-3 and Exp-4 (Table 5). Yields from insecticide-treated plots were higher by $346 \mathrm{~kg} / \mathrm{ha}$ and $1338 \mathrm{~kg} / \mathrm{ha}$ in Exp-3 and Exp-4, respectively. The interaction between AM fungi and insecticide treatments did not affect rice yields in any of the experiments (Table 5, Fig. 5B). A combined analysis of yields from all four experiments showed that AM fungi-treated plots had significantly higher yields compared to non-AM fungi plots $\left(F_{1,148}=16.90, P<0.0001\right)$, and that NipsIt INSIDE-treated plots had significantly higher yields compared to untreated plots $\left(F_{1,148}=14.73, P=0.0002\right)$.

Percent yield losses $(\mathrm{kg} / \mathrm{ha})$ did not differ between AMF-treated and untreated plots in any of the four experiments (Table 6). However, plots inoculated with AM fungi showed a trend toward higher yield losses from weevils in all four experiments relative to plots not inoculated with AM fungi (Table 6). A combined analysis to compare yield loss in AM fungi plots with yield loss in

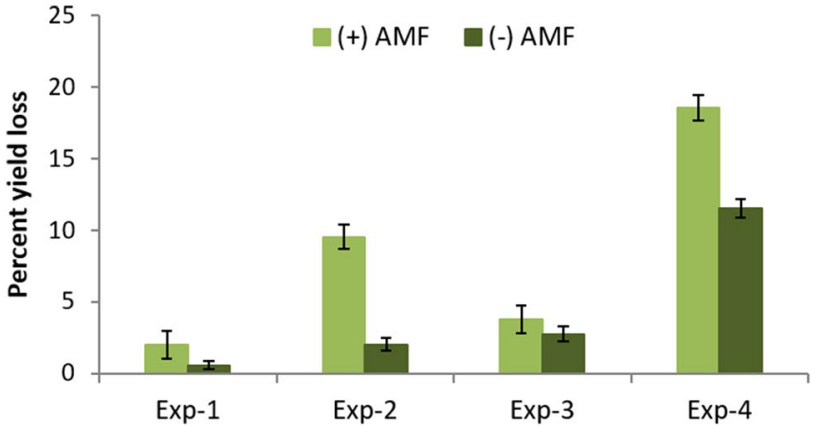

Fig. 6 Percent yield losses $( \pm$ SE) attributable to herbivory by rice water weevils root injury in four experiments conducted in the field over 3 years (2016-2018)

plots not inoculated with AM fungi across all four experiments also showed no significant differences in yield loss $\left(F_{1,72.1}=1.04, P=0.312\right)$. Yield losses from weevils in the presence of AM fungi ranged from 2 to $19 \%$ depending on the experiment, while yield losses from weevils in the absence of AM fungi ranged from 1 to $12 \%$ (Fig. 6). 


\section{Discussion}

Inoculation of soil with $\mathrm{AM}$ fungi has been suggested as a sustainable approach to overcome reductions in crop yields caused by insect pests by altering the physiological and biochemical properties of the crop plant (Bennett et al. 2006; Wang et al. 2015). Environmental factors influence the quantity, effectiveness, and nature of resource exchange among AM fungi and their hosts (Bever 2015; Hoeksema et al. 2010; Johnson et al. 2010; Pineda et al. 2013; Wardle et al. 2004), and thus, the effects of AM fungi on their hosts are variable. On the one hand, positive effects of AM fungi on plant growth and nutrient concentrations (Solaiman and Hirata 1996, 1997), defense against pathogens (Campos-Soriano et al. 2011; Liu et al. 2007; Pozo et al. 2002), and photosynthetic rates (Black et al. 2000) have been shown in several studies. On the other hand, negative effects of AM fungi on resistance to herbivores have also been documented in rice and other systems (Bernaola et al. 2018b; Cosme et al. 2011; Simon et al. 2017). However, the impact of inoculation with AM fungi on the tolerance of plants to herbivory injury, particularly root injury, has not been well studied. In the current study, we provide robust field data that quantify the impact of inoculating rice seeds with AM fungi on plant growth, nutritional status, resistance and tolerance to herbivory, and yield. Overall, our findings clearly show that AM fungi root colonization influenced herbivore resistance, plant growth, and yield, but evidence for a positive effect of AM fungi on tolerance to root herbivory was ambiguous.

\section{Effects of AM fungi on plant resistance to herbivory}

Colonization of roots with AM fungi can alter interactions with insect herbivores, with positive, negative, or mixed effects (Gange 2001; Hartley and Gange 2009; Koricheva et al. 2009). Consistent with previous studies in rice (Bernaola et al. 2018b; Bernaola and Stout 2019; Cosme et al. 2011), we found that inoculation of plots with AM fungi compromised resistance to rice water weevil, a root-feeding chewing insect, as evidenced by their higher larval densities. Bernaola et al. (2018b) showed that AM fungi inoculation also increased the susceptibility of rice to two other pests: a defoliating insect, fall armyworm (Spodoptera frugiperda), and a soilborne pathogen, sheath blight of rice (Rhizoctonia solani). In addition, we also found in the current study increased numbers of whiteheads in plots with AM fungi. To our knowledge, this study is the first field study to report that inoculation by AM fungi affects resistance to stem borers, a globally important group of pests in rice. In contrast, inoculation with endophytic fungi in sweet sorghum leaves was found to greatly increase larval mortality of the Mediterranean corn stalk borer (Sesamia nonagrioides) and reduce stem-tunneling activities in a field study (Mantzoukas et al. 2015). Overall, this study and our previous study (Bernaola et al. 2018b) show that inoculation with AM fungi affects pests in four different feeding guilds: root-feeding, stem-boring, defoliating insects, and necrotrophic pathogen.

The specific mechanisms by which AM fungi increased susceptibility to herbivores are unclear. Possible explanations include enhancement of plant nutrient concentrations, alteration of plant defense chemistry or signaling pathways, or increases in plant biomass. Contrary to Cosme et al. (2011), increased susceptibility to herbivores in plots inoculated with AM fungi in this study was not associated with enhanced nitrogen and phosphorus concentrations, but was associated with increases in root or shoot biomass in the field plots of this study. Given the lack of effect of AM fungi on nutrient concentrations, Bernaola et al. (2018b) speculated that root colonization by AM fungi was altering defense signaling pathways, including the partly antagonistic salicylic acid and jasmonic acid pathways (Herrera-Medina et al. 2008). The ability of AM fungi to alter the resistance of rice plants opens new avenues for understanding mechanisms underlying susceptibility to herbivores. Consequently, mycorrhiza-induced susceptibility in rice should be given greater consideration as in other crop systems (Miozzi et al. 2019; Simon et al. 2017).

\section{Effects of AM fungi on plant tolerance to root feeding}

In an agricultural context, plant tolerance, which is defined as the ability of a plant to ameliorate the effects of herbivore injury on crop yield, is measured by estimating yield differences between injured and uninjured plants (Garrido et al. 2010; Strauss and Agrawal 1999). We hypothesized that mutualistic associations with AM fungi would help rice plants tolerate root injury caused by rice water weevil, which would translate into less yield loss in inoculated plots than in non-inoculated plots. However, we found no evidence that colonization by AM fungi reduced percent yield loss from root herbivory; in fact, percent yield losses attributable to injury by larval rice water weevil trended (non-significantly) higher in the presence of AM fungi than in the absence of AM fungi, although overall yields were still higher in AMFinoculated plots. Yield losses ranged from $2.3 \%$ to $19 \%$ in plots inoculated with AM fungi versus $0.8 \%$ to $12 \%$ in noninoculated plots. In contrast to the large number of studies investigating effects of AM fungi on plant resistance, there are only a few greenhouse and laboratory studies investigating the effects of AM fungi or other endophytes on the 
tolerance of crop plants following injury by root herbivores. For instance, Gange et al. (1994) found that AM fungi colonization of dandelion plants mitigated the effects of black vine weevil (Otiorhynchus sulcatus) at low larval density. Currie et al. (2011) and (Gange 2001) found that white clover plants inoculated with AM fungi were able to tolerate the effects of root loss by the larvae of the clover root weevil (Sitona lepidus). In contrast, Gan et al. (2017) reported that multiple species of root endophyte reduced plant tolerance following root damage, including a reduction in plant regrowth following damage. In rice in particular, Cosme et al. (2016) recently found that colonization of rice plant roots by the non-mycorrhizal endophytic fungus Piriformospora indica could mitigate the effects of root injury on rice growth in a greenhouse experiment. While these examples do not explicitly address yield losses in relation to root herbivory, they do relate tolerance-related traits to mutualistic associations in their respective systems. Since this is the first field study to demonstrate the impact of this tripartite interaction between rice, insects, and fungi on tolerance, further studies like this are needed to improve our knowledge of the effect of AM fungi on tolerance to below-ground insects.

\section{Effects of AM fungi on rice growth and yield}

Despite the fact that percent yield losses were not lower in the presence of AM fungi, two lines of evidence nonetheless suggested that AM fungi could stimulate rice tolerance to root herbivory under some conditions. First, total yields were higher in plots inoculated with AM fungi despite the presence of higher densities of weevils and stem borers (whiteheads) in AM fungi plots. Yields in inoculated plots were higher in Exp-1, Exp-2, and Exp-4 by 5\%, 14\%, and $13 \%$, respectively, when compared to non-AM fungi plots, even though weevil densities were $12 \%, 24 \%$, and $11 \%$ higher, respectively, and whitehead densities were $97 \%$, $100 \%$, and $36 \%$ higher, respectively, in these plots than in non-AM fungi plots.

Second, plant biomasses were higher in plots inoculated with AM fungi than in non-inoculated plots. The effects of AM fungi on plant growth differed before and after floods were established in rice plots. Before flooding, when root injury by rice water weevil was minimal (oviposition by rice water weevil occurs only under flooded conditions), inoculation with AM fungi increased root biomass by $35 \%, 43 \%$, and $68 \%$, in Exp-1, Exp-2, and Exp-3, respectively, compared to non-inoculated plots; after flooding, when infestation of roots by rice water weevil had occurred, inoculation with AM fungi increased shoot biomass in Exp-2, Exp-3, and Exp-4 by 19\%, 45\%, and 46\%, respectively. Increases in both root and shoot biomass in weevil-injured rice may have contributed to higher yields in the presence of weevils. According to the "modification of tolerance hypothesis," suggested by Bennett et al. (2006), AM fungi can increase the tolerance of plants to biotic stresses by contributing to the ability of plants to grow following herbivore injury. In the current study, inoculation with AM fungi may have reduced the negative effects of root injury and other possible biotic stresses, such as the presence of whiteheads, by increasing plant biomass in plots inoculated with AM fungi. At the least, our results show that the presence of herbivores does not prevent the ability of plants to benefit from AM fungi under field conditions.

Increases in plant biomasses and yields in response to inoculation with AM fungi in the absence of biotic stresses have been repeatedly demonstrated in agricultural and natural ecosystems. Beneficial effects of AM fungi on rice yields have previously been reported, but none of these prior reports involved rice infested with insects. Sisaphaithong et al. (2017) conducted two field experiments in Japan showing that one of three varieties used, ARC5955, exhibited a strong tendency toward higher yields (up to 42\%) in AM fungi-treated plots. In another study, inoculation with AM fungi increased grain yields by 14 to $21 \%$ under field conditions (Solaiman and Hirata 1997). Similarly, Diedhiou et al. (2016) showed that upland rice varieties treated with AM fungi exhibited higher grain yields (up to 52\%) when compared to non-inoculated plants under field conditions. In addition, the combined effects of AM fungi and free-living nitrogen-fixing bacteria (Herbaspirillum seropedicae) significantly increased root and shoot biomass and yield of wetland rice (Hoseinzade et al. 2016). Stimulation of plant growth and yields in response to AM fungi has also been reported in legumes: field inoculation of Medicago sativa by two non-native mycorrhizal inoculants stimulated biomass production and yield, and this effect persisted in the field up to 2 years after application of AM fungi (Pellegrino et al. 2012). Furthermore, a meta-analysis of field studies on inoculation of wheat with AM fungi showed increases in above-ground biomass, nutrient uptake, and yields in inoculated plants (Pellegrino et al. 2015). Also, a global metaanalysis of field studies with major cereal crops including wheat, maize, rice, and sorghum demonstrated an overall $16 \%$ increase in yield due to inoculation with AM fungi (Zhang et al. 2019). Although the effects of AM fungi on yields can be variable, with environment- and crop-specific effects, these meta-analyses still highlight the importance of integrating AM fungi in sustainable agriculture to increase yield production of cereal crops (Pellegrino et al. 2015; Zhang et al. 2019).

\section{Caveats in this study}

Although these experiments failed to detect differences in percent yield losses from weevils in plots inoculated and non-inoculated with AM fungi, a number of factors 
interfered with our ability to detect such differences, and further research will be needed. The first of these factors was the lack of large differences in AM fungi colonization among AM fungi and non-AM fungi treatments in some of the experiments. It is well recognized that root colonization by AM fungi is sensitive to soil conditions. Soil from experimental fields in 2016 had higher cation exchange capacity compared to the following years, and soils in 2017 and 2018 were slightly higher in organic matter content, $\mathrm{P}$, and $\mathrm{K}$, perhaps due to differences in historical fertilizer use in fields (Table S2). Soil fertility, cropping history, and agronomic management practices can affect early sporulation and colonization by AM fungi (Smith and Read 2008), and differences in these factors could explain patterns in percent colonization by AM fungi in roots among years.

One factor contributing to the small differences in AM fungi colonization among treatments was the moderately high colonization in non-inoculated plots. Results showed that colonization by AM fungi in non-inoculated rice plots ranged from 12 to $50 \%$, indicating that fields supported a native AM fungi community (Fig. 1). The presence of native AM fungi in southern rice soils has been demonstrated previously (Bernaola et al. 2018a). Although colonization by AM fungi in non-inoculated rice plants was moderately high, the fact that experimentally inoculated plots had the highest rates of root colonization in AM fungi-inoculated plants in all experiments, ranging from 45 to $74 \%$, suggests that inoculation with AM fungi successfully enhanced natural colonization in these plots. Moreover, the strong effects of experimental inoculation on rice growth and yield corroborates the efficacy of experimental inoculation in this study. A recent work by Cely et al. (2016) also showed moderate rates (ca. 50\%) of AM fungi colonization in control (noninoculated) plants. However, inoculation with AM fungi in treated plants within the same study indicated that agricultural soils not only supported an indigenous community of AM fungi, but also showed that inoculation with AM fungi enhanced both plant growth and yield in soybean and cotton plants to an extent similar to that observed in our current study in rice.

Of particular note with respect to AM fungi colonization levels was Exp-2, which overall showed the highest levels of AM fungi root colonization, but which also showed the lowest yields. One reason for this discrepancy was the challenging weather conditions experienced in 2017. High rainfall in early March impacted seed germination and stand establishment in this experiment (Figure S2). In addition, a tropical storm in June also impacted yields. Despite unfavorable weather in Exp-2, plots inoculated with AM fungi showed higher yields than non-inoculated plots.

Another factor that interfered with the ability to detect differences in tolerance between AM fungi-inoculated and non-inoculated plots was the apparent interference of the insecticide used with colonization by AM fungi. Rates of root colonization were lower in the presence of NipsIt INSIDE than in AM fungi-only treatments in Exp-1, Exp-2, and Exp-4. Deleterious effects of the insecticide Selecron (Profenofos) on root colonization by AM fungi were reported earlier in legumes (Abd-Alla et al. 2000). Insecticidal substances applied directly to the crop plant in the form of seed treatments could be active when AM fungi are still in the pre-symbiotic stage and may directly affect the establishment of associations between roots and AM fungi (HageAhmed et al. 2019). In addition, neonicotinoid insecticides can induce the expression of the salicylic acid (SA) pathway in plants (Ford et al. 2010; Wulff et al. 2019). Because activation of the SA pathway often reduces infection by fungal pathogens, it is possible that NipsIt INSIDE reduced colonization by AM fungi by upregulating antifungal defenses or interfering with synthesis of cell wall components essential for the establishment of root colonization. Further study is needed to evaluate potential interactions between neonicotinoids and other insecticides and root colonization by AM fungi. Such negative interactions would be of considerable importance globally, because neonicotinoids are the most widely used class of insecticides in the world.

It is a matter of debate whether percent colonization by AM fungi is always a good index of the effect of inoculation by the fungi on the host plant. For instance, several authors have found no significant association between responses in plant biomass and the percentage of roots colonized by endomycorrhizal fungi (Martin et al. 2012; Sawers et al. 2017; Smith et al. 2004). Barber et al. (2013a) also showed that percentage of AM fungi colonization was not correlated with any measured plant traits. In addition, it is also possible that the AM fungi species found in the commercial inoculant used in this study displaced indigenous AM fungi in inoculated plots and that these new mycorrhizal species were more effective at increasing plant growth and yields than the indigenous species. This displacement would lead to increases in plant growth and yield without affecting percent colonization. Therefore, the higher yields and biomass found in this study may have been a better indicator of the success of experimental inoculation with AM fungi than percent root colonization.

The low efficacy of neonicotinoids against rice water weevils may also have obscured the effects of AM fungi on tolerance of rice to root injury. The NipsIt INSIDE seed treatment reduced densities of weevil larvae by only about $50 \%$, and thus, the impact of weevil feeding on yields may have been underestimated and the influence of AM fungi on yield losses obscured. Since this is the first study exploring plant tolerance following herbivore injury in rice plants inoculated with AM fungi, future studies should employ insecticides that are more effective against rice water weevil or other rice pests. 
Yet another factor that interfered with the ability to determine the impact of AM fungi on tolerance was the unexpected presence of stem borers, which may have caused yield losses in addition to those caused by weevils. Experimental inoculation with AM fungi increased the incidence of whiteheads in Exp-1 and -4, and insecticidal seed treatments significantly reduced whiteheads densities only in Exp-4. Thus, potential yield losses caused by stem borer infestation may have interfered with the ability to detect possible increases in tolerance to weevil injury caused by AM fungi. This study is the first to demonstrate that inoculation with AM fungi can increase susceptibility to stem borers in addition to the rice water weevil and other pests (Bernaola et al. 2018b), and also the first report in rice that neonicotinoids may affect stem borers.

Finally, our experiments used only a single cultivar, 'CL111,' to investigate the effects of mycorrhizae on rice tolerance to pests. Rice cultivars grown in Louisiana respond differently to rice water weevil feeding (Zou et al. 2004) and using a single commercial variety may not have allowed a comprehensive understanding of the effects of AM fungi on rice responses to root injury. Further research with a greater range of varieties to determine whether AM fungi have the potential to increase plant tolerance not only to the rice water weevil but also to stem borers is needed.

This study demonstrated, using well-replicated field experiments, that inoculation with AM fungi had beneficial effects on plant growth and yields. The fact that treatment of seeds with AM fungi increased growth and yield of rice plants despite the presence of higher populations of both weevils and stem borers suggests the possibility that AM fungi increased plant tolerance to root injury and the feasibility of using seed treatments of AM fungi as a part of rice crop production in the southern USA. A better understanding of how the use of these beneficial organisms can be optimized will be necessary to successfully incorporate them into sustainable crop production. In particular, a number of factors obscured the potential effects of AM fungi on plant tolerance, and additional studies will be needed to disentangle the various factors that might have impacted the ability of AM fungi to increase rice tolerance. These studies should be conducted using different formulations of AM fungi, including species endemic to rice fields, different insecticides with greater efficacy against weevils, and a wider range of rice varieties in order to determine whether AM fungi can enhance rice tolerance to root injury.

\section{Author contribution}

LB and MJS conceived the experiment. LB and MJS designed the experiment. LB conducted, collected, and analyzed the data for the experiments. LB treated and analyzed rice roots for quantifying AM fungi colonization. LB wrote the first draft manuscript, MJS provided edits, and all authors agreed on the final manuscript.

Acknowledgements The authors would like to thank Joe Wang from Valent USA for treating the rice seeds for the experiments conducted, Marty J. Frey for the support and assistance in the field experiments, and Dr. Wellington Eduardo for technical assistance.

Funding Funding for this study was provided by Valent USA and USDA-NIFA, Applied Research and Development Program (Award No. 2014-70006-22529).

Availability of data and material The authors declare that data supporting the findings of this study are available within the article (and its supplementary information file).

\section{Compliance with ethical standards}

Conflict of interest The authors do not have any conflicts of interest.

Code availability Not applicable.

Open Access This article is licensed under a Creative Commons Attribution 4.0 International License, which permits use, sharing, adaptation, distribution and reproduction in any medium or format, as long as you give appropriate credit to the original author(s) and the source, provide a link to the Creative Commons licence, and indicate if changes were made. The images or other third party material in this article are included in the article's Creative Commons licence, unless indicated otherwise in a credit line to the material. If material is not included in the article's Creative Commons licence and your intended use is not permitted by statutory regulation or exceeds the permitted use, you will need to obtain permission directly from the copyright holder. To view a copy of this licence, visit http://creativecommons.org/licenses/by/4.0/.

\section{References}

Abd-Alla MH, Omar SA, Karanxha S (2000) The impact of pesticides on arbuscular mycorrhizal and nitrogen-fixing symbioses in legumes. Appl Soil Ecol 14:191-200. https://doi.org/10.1016/S0929 -1393(00)00056-1

Agrawal AA, Hastings AP, Johnson MTJ, Maron JL, Salminen J-P (2012) Insect herbivores drive real-time ecological and evolutionary change in plant populations. Science 338:113-116. https://doi. org/10.1126/science. 1225977

Angelard C, Colard A, Niculita-Hirzel H, Croll D, Sanders IR (2010) Segregation in a mycorrhizal fungus alters rice growth and symbiosis-specific gene transcription. Curr Biol 20:1216-1221. https ://doi.org/10.1016/j.cub.2010.05.031

Barber N, Kiers ET, Theis N, Hazzard RV, Adler LS (2013a) Linking agricultural practices, mycorrhizal fungi, and traits mediating plant-insect interactions. Ecol Appl 23:1519-1530. https://doi. org/10.1890/13-0156.1

Barber NA, Kiers ET, Hazzard RV, Adler LS (2013b) Context-dependency of arbuscular mycorrhizal fungi on plant-insect interactions in agroecosystems. Front Plant Sci 338:1-10. https://doi. org/10.3389/fpls.2013.00338

Bennett AE, Bever JD (2007) Mycorrhizal species differentially alter plant growth and response to herbivory. Ecology 88:210-218 
Bennett AE, Alers-Garcia J, Bever JD (2006) Three-way interactions among mutualistic mycorrhizal fungi, plants, and plant enemies: hypotheses and synthesis. Am Nat 167:141-152. https://doi. org/10.1086/499379

Bennett AE, Bever JD, Deane Bowers M (2009) Arbuscular mycorrhizal fungal species suppress inducible plant responses and alter defensive strategies following herbivory. Oecologia 160:771-779. https://doi.org/10.1007/s00442-009-1338-5

Bernaola L, Stout MJ (2019) Effects of arbuscular mycorrhizal fungi on rice-herbivore interactions are soil-dependent. Sci Rep 9:14037. https://doi.org/10.1038/s41598-019-50354-2

Bernaola L, Cange G, Way MO, Gore J, Hardke J, Stout M (2018a) Natural colonization of rice by arbuscular mycorrhizal fungi in different production areas. Rice Sci 25:169-174. https://doi. org/10.1016/j.rsci.2018.02.006

Bernaola L, Cosme M, Schneider RW, Stout M (2018b) Belowground inoculation with arbuscular mycorrhizal fungi increases local and systemic susceptibility of rice plants to different pest organisms. Front Plant Sci 9:747. https://doi.org/10.3389/ fpls.2018.00747

Bever JD (2015) Preferential allocation, physio-evolutionary feedbacks, and the stability and environmental patterns of mutualism between plants and their root symbionts. New Phytol 205:1503-1514. https ://doi.org/10.1111/nph.13239

Black KG, Mitchell DT, Osborne BA (2000) Effect of mycorrhizalenhanced leaf phosphate status on carbon partitioning, translocation and photosynthesis in cucumber. Plant Cell Environ 23:797809. https://doi.org/10.1046/j.1365-3040.2000.00598.x

Blanche B, Harrell D, Saichuk JK (2009) General agronomic guidelines. In: Saichuk JK (ed) Rice production handbook, 3e16th edn. LSU AgCenter, Baton Rouge, pp 4-15

Borowicz VA (2001) Do Arbuscular mycorrhizal fungi alter plant-pathogen relations? Ecology 82:3057-3068. https:// doi.org/10.1890/0012-9658(2001)082\%5b3057:DAMFA P\%5d2.0.CO;210.1890/0012-9658(2001)082\%5b3057:DAMFA $\mathrm{P} \% 5 \mathrm{~d} 2.0 . \mathrm{CO} ; 2$

Borowicz VA (2009) Organic farm soil improves strawberry growth but does not diminish spittlebug damage. J Sustain Agric 33:177-188. https://doi.org/10.1080/10440040802660087

Borowicz VA (2013) The impact of arbuscular mycorrhizal fungi on plant growth following herbivory: a search for pattern. Acta Oecol 52:1-9. https://doi.org/10.1016/j.actao.2013.06.004

Byrne DH, Guerrero JM, Bellotti AC, Gracen VE (1982) Yield and plant growth responses of mononychellus mite resistant and susceptible cassava cultivars under protected versus infested conditions. Crop Sci 22:486-490. https://doi.org/10.2135/cropsci198 2.0011183X002200030011x

Campos-Soriano L, Garcia-Martinez J, San Segundo B (2011) The arbuscular mycorrhizal symbiosis promotes the systemic induction of regulatory defence-related genes in rice leaves and confers resistance to pathogen infection. Molec Plant Pathol 13:579-592. https://doi.org/10.1111/j.1364-3703.2011.00773.x

Cely MVT et al (2016) Inoculant of arbuscular mycorrhizal fungi (Rhizophagus clarus) increase yield of soybean and cotton under field conditions. Front Microbiol. https://doi.org/10.3389/fmicb .2016 .00720

Colard A, Angelard C, Sanders IR (2011) Genetic exchange in an arbuscular mycorrhizal fungus results in increased rice growth and altered mycorrhiza-specific gene transcription. Appl Environ Microbiol 77:6510-6515. https://doi.org/10.1128/AEM.05696-11

Cosme M, Stout MJ, Wurst S (2011) Effect of arbuscular mycorrhizal fungi (Glomus intraradices) on the oviposition of rice water weevil (Lissorhoptrus oryzophilus). Mycorrhiza 21:651-658. https:// doi.org/10.1007/s00572-011-0399-6

Cosme M, Lu J, Erb M, Stout MJ, Franken P, Wurst S (2016) A fungal endophyte helps plants to tolerate root herbivory through changes in gibberellin and jasmonate signaling. New Phytol 211:10651076. https://doi.org/10.1111/nph.13957

Currie AF, Murray PJ, Gange AC (2011) Is a specialist root-feeding insect affected by arbuscular mycorrhizal fungi? Appl Soil Ecol 47:77-83. https://doi.org/10.1016/j.apsoil.2010.12.002

Diedhiou AG et al (2016) Field trials reveal ecotype-specific responses to mycorrhizal inoculation in rice. PLoS ONE 11:e0167014. https ://doi.org/10.1371/journal.pone.0167014

Ford KA et al (2010) Neonicotinoid insecticides induce salicylate-associated plant defense responses. Proc Natl Acad Sci 107:1752717532. https://doi.org/10.1073/pnas.1013020107

Gan H, Churchill ACL, Wickings K (2017) Invisible but consequential: root endophytic fungi have variable effects on belowground plantinsect interactions. Ecosphere 8:e01710. https://doi.org/10.1002/ ecs 2.1710

Gange AC (2001) Species-specific responses of a root- and shootfeeding insect to arbuscular mycorrhizal colonization of its host plant. New Phytol 150:611-618. https://doi.org/10.104 6/j.1469-8137.2001.00137.x

Gange AC, West HM (1994) Interactions between arbuscular mycorrhizal fungi and foliar-feeding insects in Plantago lanceolata $\mathrm{L}$. New Phytol 128:79-87. https://doi.org/10.1111/j.1469-8137.1994. tb03989.x

Gange AC, Brown VK, Sinclair GS (1994) Reduction of black vine weevil larval growth by vesicular-arbuscular mycorrhizal infection. Entomol Exp Appl 70:115-119. https://doi. org/10.1111/j.1570-7458.1994.tb00739.x

Garrido E, Bennett AE, Fornoni J, Strauss SY (2010) Variation in arbuscular mycorrhizal fungi colonization modifies the expression of tolerance to above-ground defoliation. J Ecol 98:43-49. https ://doi.org/10.1111/j.1365-2745.2009.01586.x

Garrido E, Díaz MF, Bernal H, Nustez CE, Thaler J, Jander G, Poveda $\mathrm{K}$ (2017) Costs and tradeoffs of resistance and tolerance to belowground herbivory in potato. PLoS ONE 12:e0169083. https://doi. org/10.1371/journal.pone.0169083

Gehring C, Bennett A (2009) Mycorrhizal fungal-plant-insect interactions: the importance of a community approach. Environ Entomol 38:93-102. https://doi.org/10.1603/022.038.0111

Hage-Ahmed K, Rosner K, Steinkellner S (2019) Arbuscular mycorrhizal fungi and their response to pesticides. Pest Manag Sci 75:583-590. https://doi.org/10.1002/ps.5220

Hamm JC, Stout MJ, Riggio RM (2010) Herbivore- and elicitorinduced resistance in rice to the rice water weevil (Lissorhoptrus oryzophilus Kuschel) in the laboratory and field. J Chem Ecol 36:192-199. https://doi.org/10.1007/s10886-010-9751-0

Hamm J, Lanka S, Stout M (2014) Influence of rice seeding rate on efficacies of neonicotinoid and anthranilic diamide seed treatments against rice water weevil. Insects 5:961-973. https://doi. org/10.3390/insects5040961

Hartley SE, Gange AC (2009) Impacts of plant symbiotic fungi on insect herbivores: mutualism in a multitrophic context. Annu Rev Entomol 54:323-342. https://doi.org/10.1146/annur ev.ento.54.110807.090614

Herrera-Medina MJ, Tamayo MI, Vierheilig H, Ocampo JA, GarcíaGarrido JM (2008) The jasmonic acid signalling pathway restricts the development of the arbuscular mycorrhizal association in tomato. J Plant Growth Regul 27:221-230. https://doi. org/10.1007/s00344-008-9049-4

Hoeksema JD et al (2010) A meta-analysis of context-dependency in plant response to inoculation with mycorrhizal fungi. Ecol Lett 13:394-407. https://doi.org/10.1111/j.1461-0248.2009.01430.x

Hoseinzade H, Ardakani MR, Shahdi A, Rahmani HA, Noormohammadi G, Miransari M (2016) Rice (Oryza sativa L.) nutrient management using mycorrhizal fungi and endophytic Herbaspirillum seropedicae. J Integr Agric 15:1385-1394. https://doi. org/10.1016/S2095-3119(15)61241-2 
Hummel NA, Stout MJ (2009) Rice water weevil control with clothianidin seed treatment, 2008. Arthropod Manag Tests. https://doi. org/10.4182/amt.2009.F50

Hummel NA, Mészáros A, Ring DR, Beuzelin JM, Stout MJ (2014) Evaluation of seed treatment insecticides for management of the rice water weevil, Lissorhoptrus oryzophilus Kuschel (Coleoptera: Curculionidae), in commercial rice fields in Louisiana. Crop Protect 65:37-42. https://doi.org/10.1016/j.cropro.2014.06.025

Johnson NC, Wilson GWT, Bowker MA, Wilson JA, Miller RM (2010) Resource limitation is a driver of local adaptation in mycorrhizal symbioses. Proc Natl Acad Sci 107:2093-2098. https://doi. org/10.1073/pnas.0906710107

Johnson SN, Erb M, Hartley SE (2016) Roots under attack: contrasting plant responses to below- and aboveground insect herbivory. New Phytol 210:413-418. https://doi.org/10.1111/nph.13807

Kempel A, Schmidt AK, Brandl R, Schädler M (2010) Support from the underground: induced plant resistance depends on arbuscular mycorrhizal fungi. Funct Ecol 24:293-300. https://doi.org/10.11 11/j.1365-2435.2009.01647.x

Koch KG, Chapman K, Louis J, Heng-Moss T, Sarath G (2016) Plant tolerance: a unique approach to control hemipteran pests. Front Plant Sci. https://doi.org/10.3389/fpls.2016.01363

Koricheva J, Gange AC, Jones T (2009) Effects of mycorrhizal fungi on insect herbivores: a meta-analysis. Ecology 90:2088-2097. https ://doi.org/10.1890/08-1555.1

Koske RE, Gemma JN (1989) A modified procedure for staining roots to detect VA mycorrhizas. Mycol Res 92:486-488. https://doi. org/10.1016/S0953-7562(89)80195-9

Li H, Ye ZH, Chan WF, Chen XW, Wu FY, Wu SC, Wong MH (2011) Can arbuscular mycorrhizal fungi improve grain yield, as uptake and tolerance of rice grown under aerobic conditions? Environ Pollut 159:2537-2545. https://doi.org/10.1016/j.envpo 1.2011.06.017

Liu J, Maldonado-Mendoza I, Lopez-Meyer M, Cheung F, Town CD, Harrison MJ (2007) Arbuscular mycorrhizal symbiosis is accompanied by local and systemic alterations in gene expression and an increase in disease resistance in the shoots. Plant J 50:529-544. https://doi.org/10.1111/j.1365-313X.2007.03069.x

$\mathrm{Lu} \mathrm{J}$ et al (2015) Induced jasmonate signaling leads to contrasting effects on root damage and herbivore performance. Plant Physiol 167:1100-1116. https://doi.org/10.1104/pp.114.252700

Luginbuehl LH et al (2017) Fatty acids in arbuscular mycorrhizal fungi are synthesized by the host plant. Science 356:1175-1178. https ://doi.org/10.1126/science.aan0081

Lv J, Wilson LT, Longnecker MT (2008) Tolerance and compensatory response of rice to sugarcane borer (Lepidoptera: Crambidae) Injury. Environ Entomol 37(796-807):712

Mantzoukas S, Chondrogiannis C, Grammatikopoulos G (2015) Effects of three endophytic entomopathogens on sweet sorghum and on the larvae of the stalk borer Sesamia nonagrioides. Entomol Exp Appl 154:78-87. https://doi.org/10.1111/eea.12262

Martin SL, Mooney SJ, Dickinson MJ, West HM (2012) The effects of simultaneous root colonisation by three Glomus species on soil pore characteristics. Soil Biol Biochem 49:167-173. https://doi. org/10.1016/j.soilbio.2012.02.036

McGonigle TP, Miller MH, Evans DG, Fairchild GL, Swan JA (1990) A new method which gives an objective measure of colonization of roots by vesicular-arbuscular mycorrhizal fungi. New Phytol 115:495-501. https://doi.org/10.1111/j.1469-8137.1990. tb00476.x

Miozzi L, Vaira AM, Catoni M, Fiorilli V, Accotto GP, Lanfranco L (2019) Arbuscular mycorrhizal symbiosis: plant friend or foe in the fight against viruses? Front Microbiol. https://doi.org/10.3389/ fmicb.2019.01238

Mitchell C, Brennan RM, Graham J, Karley AJ (2016) Plant defense against herbivorous pests: exploiting resistance and tolerance traits for sustainable crop protection. Front Plant Sci 7:1132. https://doi.org/10.3389/fpls.2016.01132

N'Guessan FK, Quisenberry SS, Thompson RA, Linscombe SD (1994) Assessment of Louisiana rice breeding lines for tolerance to the rice water weevil (Coleoptera: Curculionidae). J Econ Entomol 87:476-481. https://doi.org/10.1093/jee/87.2.476

Pellegrino E, Turrini A, Gamper HA, Cafa G, Bonari E, Young JP, Giovannetti M (2012) Establishment, persistence and effectiveness of arbuscular mycorrhizal fungal inoculants in the field revealed using molecular genetic tracing and measurement of yield components. New Phytol 194:810-822. https://doi.org/1 0.1111/j.1469-8137.2012.04090.x

Pellegrino E, Öpik M, Bonari E, Ercoli L (2015) Responses of wheat to arbuscular mycorrhizal fungi: a meta-analysis of field studies from 1975 to 2013. Soil Biol Biochem 84:210-217. https://doi. org/10.1016/j.soilbio.2015.02.020

Peterson RKD, Varella AC, Higley LG (2017) Tolerance: the forgotten child of plant resistance. PeerJ 5:e3934. https://doi. org/10.7717/peerj.3934

Pineda A, Dicke M, Pieterse CMJ, Pozo MJ, Biere A (2013) Beneficial microbes in a changing environment: are they always helping plants to deal with insects? Funct Ecol 27:574-586. https://doi.org/10.1111/1365-2435.12050

Pozo MJ, Cordier C, Dumas-Gaudot E, Gianinazzi S, Barea JM, Azcon-Aguilar C (2002) Localized versus systemic effect of arbuscular mycorrhizal fungi on defence responses to Phytophthora infection in tomato plants. J Exp Bot 53:525-534

Robert CAM et al (2014) Induced carbon reallocation and compensatory growth as root herbivore tolerance mechanisms. Plant Cell Environ 37:2613-2622. https://doi.org/10.1111/pce.12359

Robert CAM, Schirmer S, Barry J, Wade French B, Hibbard BE, Gershenzon J (2015) Belowground herbivore tolerance involves delayed overcompensatory root regrowth in maize. Entomol Exp Appl 157:113-120. https://doi.org/10.1111/eea.12346

Roger A, Colard A, Angelard C, Sanders IR (2013) Relatedness among arbuscular mycorrhizal fungi drives plant growth and intraspecific fungal coexistence. ISME J 7:2137-2146. https:// doi.org/10.1038/ismej.2013.112

Sawers RJH, Gutjahr C, Paszkowski U (2008) Cereal mycorrhiza: an ancient symbiosis in modern agriculture. Trends Plant Sci 13:1360-1385. https://doi.org/10.1016/j.tplants.2007.11.006

Sawers RJH et al (2017) Phosphorus acquisition efficiency in arbuscular mycorrhizal maize is correlated with the abundance of root-external hyphae and the accumulation of transcripts encoding PHT1 phosphate transporters. New Phytol 214:632-643. https://doi.org/10.1111/nph.14403

Schuster DJ, Price JF, Martin FG, Howard CM, Albregts EE (1980) Tolerance of strawberry cultivars to twospotted spider mites in Florida. J Econ Entomol 73:52-54. https://doi.org/10.1093/ jee/73.1.52

Simon AL, Wellham PAD, Aradottir GI, Gange AC (2017) Unravelling mycorrhiza-induced wheat susceptibility to the English grain aphid Sitobion avenae. Sci Rep 7:46497. https://doi. org/10.1038/srep46497

Sisaphaithong T et al (2017) Varietal differences in the growth responses of rice to an arbuscular mycorrhizal fungus under natural upland conditions. Plant Signal Behav 12:e1274483. https://doi.org/10.1080/15592324.2016.1274483

Smith SE, Read DJ (2008) Mycorrhizal symbiosis, 3rd edn. Academic Press, San Diego

Smith SE, Smith FA, Jakobsen I (2004) Functional diversity in arbuscular mycorrhizal (AM) symbioses: the contribution of the mycorrhizal P uptake pathway is not correlated with mycorrhizal responses in growth or total P uptake. New Phytol 162:511-524. https://doi.org/10.1111/j.1469-8137.2004.01039.x 
Solaiman MZ, Hirata H (1996) Effectiveness of arbuscular mycorrhizal colonization at nursery-stage on growth and nutrition in wetland rice (Oryza sativa L.) after transplanting under different soil fertility and water regimes. Soil Sci Plant Nutr 42:561-571. https://doi. org/10.1080/00380768.1996.10416325

Solaiman MZ, Hirata H (1997) Effect of arbuscular mycorrhizal fungi inoculation of rice seedlings at the nursery stage upon performance in the paddy field and greenhouse. Plant Soil 191:1-12. https://doi.org/10.1023/a:1004238028617

Soler R, Van der Putten WH, Harvey JA, Vet LE, Dicke M, Bezemer TM (2012) Root herbivore effects on aboveground multitrophic interactions: patterns, processes and mechanisms. J Chem Ecol 38:755-767. https://doi.org/10.1007/s10886-012-0104-z

Stout MJ (2013) Reevaluating the conceptual framework for applied research on host-plant resistance. Insect Sci 20:263-272. https:// doi.org/10.1111/1744-7917.12011

Stout MJ, Rice WC, Riggio MR, Ring DR (2000) The effects of four insecticides on the population dynamics of the rice water weevil, Lissorhoptrus oryzophilus Kuschel. J Entomol Sci 35:48-61

Stout MJ, Riggio MR, Yang Y (2009) Direct induced resistance in Oryza sativa to Spodoptera frugiperda. Environ Entomol 38:1174-1181

Stowe KA, Marquis RJ, Hochwender CG, Simms EL (2000) The evolutionary ecology of tolerance to consumer damage. Annu Rev Ecol Syst 31:565-595. https://doi.org/10.1146/annurev.ecols ys.31.1.565

Strauss SY, Agrawal AA (1999) The ecology and evolution of plant tolerance to herbivory. Trends Ecol Evol 14:179-185

USDA-ERA (2019) U.S. rice acreage, production, yield, and farm price. https://www.ers.usda.gov/data-products/rice-yearbook/ rice-yearbook/\#U.S.\%20Acreage,\%20Production,\%20Yield,\%20 and\%20Farm\%20Price. Accessed September 32019

Velusamy R, Heinrichs EA (1986) Tolerance in crop plants to insect pests. Int J Trop Insect Sci 7:689-696. https://doi.org/10.1017/ S1742758400011747
Wang Y et al (2015) Community dynamics of arbuscular mycorrhizal fungi in high-input and intensively irrigated rice cultivation systems. Appl Environ Microbiol 81:2958-2965. https://doi. org/10.1128/AEM.03769-14

Wardle DA, Bardgett RD, Klironomos JN, Setala H, van der Putten WH, Wall DH (2004) Ecological linkages between aboveground and belowground biota. Science 304:1629-1633. https://doi. org/10.1126/science. 1094875

Way MO (2003) Rice arthropod pest and their management in the United States. In: Smith CW, Dilday RH (eds) Rice : origin, history, technology, and production. Wiley, Hoboken, pp 437-456

Way MO, Reay-Jones FPF, Reagan TE (2006) Resistance to stem borers (Lepidoptera: Crambidae) among Texas rice cultivars. J Econ Entomol 99:1867-1876. https://doi.org/10.1093/jee/99.5.1867

Wulff JA, Kiani M, Regan K, Eubanks MD, Szczepaniec A (2019) Neonicotinoid insecticides alter the transcriptome of soybean and decrease plant resistance. Int J Mol Sci 20:783. https://doi. org/10.3390/ijms20030783

Yang H, Dai Y, Wang X, Zhang Q, Zhu L, Bian X (2014) Meta-analysis of interactions between arbuscular mycorrhizal fungi and biotic stressors of plants. Sci World J 2014:746506. https://doi. org/10.1155/2014/746506

Zhang S, Lehmann A, Zheng W, You Z, Rillig MC (2019) Arbuscular mycorrhizal fungi increase grain yields: a meta-analysis. New Phytol 222:543-555. https://doi.org/10.1111/nph.15570

Zou L, Stout MJ, Dunand RT (2004) The effects of feeding by the rice water weevil, Lissorhoptrus oryzophilus Kuschel, on the growth and yield components of rice, Oryza sativa. Agric For Entomol 6:47-54. https://doi.org/10.1111/j.1461-9555.2004.00203.x

Publisher's Note Springer Nature remains neutral with regard to jurisdictional claims in published maps and institutional affiliations. 